\title{
On the origin of subvisible cirrus clouds in the tropical upper troposphere
}

\author{
M. Reverdy ${ }^{1}$, V. Noel ${ }^{2}$, H. Chepfer ${ }^{3}$, and B. Legras ${ }^{2}$ \\ ${ }^{1}$ CNES, Laboratoire de Meteorologie Dynamique (IPSL), UMR8539, France \\ ${ }^{2}$ CNRS, Laboratoire de Meteorologie Dynamique (IPSL), UMR8539, France \\ ${ }^{3}$ UPMC, Laboratoire de Meteorologie Dynamique (IPSL), UMR8539, France
}

Correspondence to: M. Reverdy (mathieu.reverdy@1md.polytechnique.fr)

Received: 26 April 2012 - Published in Atmos. Chem. Phys. Discuss.: 12 June 2012

Revised: 12 December 2012 - Accepted: 14 December 2012 - Published: 20 December 2012

\begin{abstract}
Spaceborne lidar observations have recently revealed a previously undetected significant population of Subvisible Cirrus (SVC). We show them to be colder than $-74^{\circ}$, with an optical depth below 0.0015 on average. The formation and persistence over time of this new cloud population could be related to several atmospheric phenomena. In this paper, we investigate if these clouds follow the same formation mechanisms as the general tropical cirrus population (including convection and in-situ ice nucleation), or if specific nucleation sites and trace species play a role in their formation. The importance of three scenarios in the formation of the global SVC population is investigated through different approaches that include comparisons with data imaging from several spaceborne instruments and back-trajectories that document the history and behavior of air masses leading to the point in time and space where subvisible cirrus were detected. In order to simplify the study of their formation, we singled out SVC with coherent temperature histories (mean variance lower than $4 \mathrm{~K}$ ) according to back-trajectories along 5,10 or 15 days (respectively 58,25 and $11 \%$ of SVC). Our results suggest that external processes, including local increases in liquid and hygroscopic aerosol concentration (either through biomass burning or volcanic injection forming sulfate-based aerosols in the troposphere or the stratosphere) have very limited short-term or mid-term impact on the SVC population. On the other hand, we find that $\sim 20 \%$ of air masses leading to SVC formation interacted with convective activity 5 days before they led to cloud formation and detection, a number that climbs to $60 \%$ over 15 days. SVC formation appears especially linked to convection over Africa and Central America, more so during JJA than DJF. These re-
\end{abstract}

sults support the view that the SVC population observed by CALIOP is an extension of the general upper tropospheric ice clouds population with its extreme thinness as its only differentiating factor.

\section{Introduction}

Subvisible cirrus (SVC) are optically thin ice clouds with optical depths below 0.03 mostly found in the tropical upper troposphere. Their existence has been known for several decades thanks to in-situ measurements from airborne probes (e.g. Heymsfield, 1986) and ground-based observations (Sassen and Cho, 1992). These studies were able to document the composition of some SVC (e.g. Davis et al., 2007; Lawson et al., 2008; Davis et al., 2010), but are hard to generalize globally. Limb observations from spaceborne instruments such as SAGE-II (Wang et al., 1994) led to important insights about these clouds, but are generally limited by a poor spatial resolution.

The role SVC play in several upper tropospheric processes is still unclear. Due to their optical transparency and cold temperatures, high tropospheric ice clouds present a limited albedo effect but some greenhouse effect, by which they modulate the global radiative budget. Most importantly, their mechanisms of formation and evolution are not well understood. This has serious implications for atmospheric physics: SVC in the Tropical Tropopause Layer (TTL, Fueglistaler et al., 2009) are often associated with the dehydration of air before it enters the stratosphere. Our poor understanding of their interaction with water vapor,

Published by Copernicus Publications on behalf of the European Geosciences Union. 
which can generate persistent supersaturation within SVC (Peter et al., 2006) means their influence as regulators at the troposphere-stratosphere interface cannot be correctly reproduced by models. This leads, among other things, to high uncertainties in the modeling of stratospheric water vapor evolution, which has consequences for climate prediction (Solomon et al., 2010).

Recent advances in signal analysis, and the availability of spaceborne active remote sensing observations, have allowed the global-scale detection of upper tropospheric layers with extremely small optical depths (down to 0.001), far thinner optically than what was previously possible using satellite observations. Most notably, observations from the Cloud-Aerosol Lidar with Orthogonal Polarization (CALIOP, Winker et al., 2009) have for the first time documented the large spatial and temporal cover of SVC (e.g. Sassen et al., 2009; Martins et al., 2011). Using the same observations, Pan and Munchak (2011) found such clouds are frequently close to the TTL and extend sometimes horizontally over several thousand kilometers. The increase in the estimated overall cover of optically very thin clouds following these discoveries means estimates of their radiative impact had to be revised (Haladay and Stephens, 2009; Yang et al., 2010; Dupont et al., 2010; Lee et al., 2009; McFarquhar et al., 2000).

In the wake of the documentation of this large number of optically thin layers, and the uncertainty surrounding their formation processes, it is important to address the question of whether SVC should be mostly considered an extension of the generic high troposphere cloud population (in which case they follow traditional cloud formation theories, including convection and in-situ ice nucleation) with small optical depths as their only specificity, or whether their formation and composition are significantly affected by specific nucleation sites or trace species (in which case they constitute a population with a unique composition and qualitatively different intrinsic properties, that needs to be addressed separately from the generic cloud population). Answering this question would shed light on the role played by SVC in atmospheric processes. For instance, the inclusion of organic aerosols, sulfate or nitric acid within nucleating ice crystals would have serious implications for the ability of SVC to dehydrate the upper troposphere, as it has been shown to severely limit water vapor deposition (Krämer et al., 2006; Murray, 2008; Grenier and Blanchet, 2010), and could explain persisting supersaturation in clear air or around SVC (Krämer et al., 2009).

Here we first document the properties of cloud layers identified as SVC in the Tropics from CALIOP observations (Sect. 2). We then document the history of air masses that led to the formation of these layers using back-trajectories (Sects. 3 and 4). By merging these results with complementary satellite data, we investigate the possibility that three phenomena affecting the atmospheric composition (nucleation of trihydrate crystals through $\mathrm{HNO}_{3}$ deposition, aerosol injection from eruptions and biomass burning and convection) have a detectable impact on the formation of these layers (Sect. 5).

\section{SVC Observations from CALIOP}

CALIOP is located on the CALIPSO satellite (CloudAerosol Lidar and Infrared Pathfinder Satellite Observation), part of the A-Train, which follows a nearly sun-synchronous orbit that crosses the equator twice per day, at 01:30 and 13:30 local time. CALIOP measures range-resolved vertical profiles of elastic backscatter at 532 and $1064 \mathrm{~nm}$, which document the vertical distribution of aerosol and cloud layers. By applying a cloud detection algorithm dedicated to optically thin layers over more than 2 years of CALIOP observations (June 2006-December 2008), we have generated a dataset of cloud base and top along the CALIPSO track with a $5 \mathrm{~km}$ resolution. The algorithm and dataset are documented at length in Martins et al. (2011). In addition, the optical depth $\tau$ of each cloud was retrieved by layer-integrating attenuated backscatter profiles from CALIOP level 1 data, following Platt et al. (2002) as

$$
\tau=\frac{1}{2 \eta} \ln \left(1-2 S \eta \gamma^{\prime}\right)
$$

where $\gamma$ ' is the total attenuated backscatter coefficient at $532 \mathrm{~nm}$ integrated over the cloud layer, $S$ is the lidar ratio and $\eta$ is the multiple scattering coefficient. As in previous works (Noel et al., 2007; Winker et al., 2009), we assumed constant values $S=25 \mathrm{sr}$ and $\eta=0.7$. The impact of these choices on the retrieved optical depth is discussed in Martins et al. (2011). The obtained dataset, called SEL2 for SubvisibleEnhanced Level 2 is available for studies focusing on subvisible cirrus at http://climserv.ipsl.polytechnique.fr/sel2.html.

CALIOP observations can be exploited to retrieve indications about the microphysical properties of particles within the SVC. In the polarization-sensitive $532 \mathrm{~nm}$ channel, the ratio of backscattered light in the perpendicular and parallel planes of polarization defines the depolarization ratio (Sassen, 1991). It depends on particle shape and is routinely used in cloud observations to discriminate liquid water droplets (spherical) from ice crystals (non-spherical). The ratio of backscattered light in the 1064 and $532 \mathrm{~nm}$ channels defines the color ratio, which provides information about particle size (Vaughan et al., 2010). Particulate backscatter was calculated by removing the molecular contribution from the CALIOP total attenuated backscatter, using the same approximation as in Martins et al. (2011). The molecular contribution had to be removed, as it can be significant in optically thin features such as SVC. Section 4 focuses on these ratios within SVC.

We identified subvisible cirrus clouds in the SEL2 database by requiring (1) layer optical depths $\tau$ below 0.03 , following the widely used convention from Sassen and Cho 

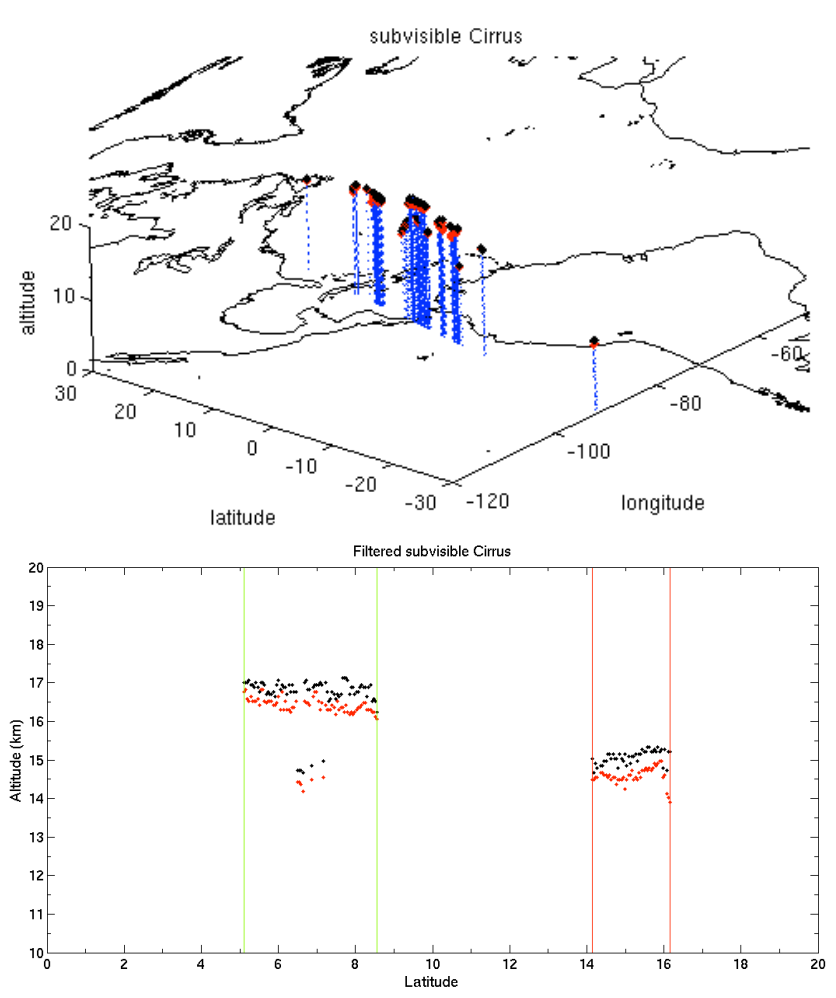

Fig. 1. (a) SVC detection along CALIPSO orbit (top) on 6 August 2007 (orbit T07-03-58ZN). Vertical profiles are shown in blue, SVC detections appear in black (cloud top) and red (cloud base). (b) Altitudes of SVC clouds remaining after layer filtering based on horizontal extent and temperature (bottom) as a function of latitude.

(1992), and (2) layer temperatures colder than $-40^{\circ}$ (to ensure only the ice phase was present), using GEOS- 5 temperatures included in CALIOP level 1 data. To limit the inclusion of spurious detection from signal noise, we restricted our analysis to SVC extending over at least $200 \mathrm{~km}$ alongtrack, or 40 consecutive $5 \mathrm{~km}$-wide profiles. Vertically contiguous layers distant horizontally by less than $10 \mathrm{~km}$ (spanning 2 profiles) were considered to be part of the same cloud. Since a large majority of cirrus clouds lie in the Tropics $\left(30^{\circ} \mathrm{S}-30^{\circ} \mathrm{N}\right)$ according to CALIOP studies (e.g. Sassen et al., 2008), we have restricted our SVC analysis to this region. Figure 1a shows an example of SVC layers detected in a single CALIPSO overpass over the Tropics on 6 August 2007 (orbit T07-03-58). The filtering described above identified two SVC in this overpass between 15 and $17 \mathrm{~km}$ of altitude (Fig. 1b), both with temperatures near $-75^{\circ}(198 \mathrm{~K})$ and optical depths near 0.004 .

We analyzed SVC during the boreal summer (JJA) and winter (DJF), the two periods with the largest tropical cirrus cover (Massie et al., 2010). Between $30^{\circ} \mathrm{S}$ and $30^{\circ} \mathrm{N}$, over the 2006-2008 period, 2810 SVC were detected in JJA and 4039 in DJF. SVC temperatures are between 185 and $215 \mathrm{~K}$ (Fig. 2, row 1) with maximum occurrence around $195 \mathrm{~K}$, and are on average $5 \mathrm{~K}$ warmer in JJA. In both seasons, SVC are
200 to $1200 \mathrm{~m}$ thick (row 2), and optically extremely thin (row 3): almost all of them exhibit $\tau<0.015$, making them Ultra Thin Tropopause Clouds (Peter et al., 2003). These clouds are most frequently a few hundred kilometers wide, but can reach several thousand kilometers on occasion (row 4 ), which explains why their average horizontal extent is close to $500 \mathrm{~km}$. While the temperature distributions are not Gaussian with a tail towards warm temperatures, the distributions of thickness are close to Gaussian both in geometrical height and optical depth. Relating these properties to specific mechanisms is not straightforward, but these observations will have to be accounted for by models of SVC generation. The horizontal extent exhibits a very skewed distribution with a long tail towards large values. This suggests a non-diffusive dispersion with large dispersion being induced by shear and filamentary structures.

The geographic distribution of SVC in a $10^{\circ} \times 10^{\circ}$ grid (Fig. 3) over the tropical region $\left( \pm 30^{\circ}\right)$ shows most are located between $10^{\circ} \mathrm{S}$ and $10^{\circ} \mathrm{N}$ along the Intertropical Convergence Zone (ITCZ), with fewer SVC closer to midlatitudes. Maxima are in regions of deep convection (Central America, Africa, Asia and Western Pacific), identified by the contour lines showing minima of outgoing longwave flux as observed by CERES over the same periods. In JJA, maxima are over the Eastern region of Asian Monsoon and the Arabian Sea. In DJF, SVC are much more numerous and maxima are over Western Pacific, Central Africa and the Amazon Basin. Cloud fractions are low over Atlantic and Eastern Pacific oceans in both seasons. This geographic distribution is consistent with Massie et al. (2010) and Martins et al. (2011).

\section{Back-trajectories}

\subsection{Model setup and initialization}

Back-trajectories use time-resolved wind fields from meteorological analysis or re-analysis to document the threedimensional time itinerary followed by air masses. By using additional fields, one can retrieve atmospheric properties (e.g. temperature) along the trajectory. We resolved backtrajectories with the TRACZILLA model (James and Legras, 2009), a modified version of the Lagrangian trajectory model FLEXPART (Stohl et al., 2005). By contrast with FLEXPART, TRACZILLA provides an advection scheme that discards the intermediate terrain following coordinate system, and performs a direct vertical interpolation of winds, linear in log-pressure, from hybrid levels (Pisso and Legras, 2008). Its reverse integration of trajectories uses wind fields from combined re-analysis and 3-h forecasts from the ECMWF (European Center of Medium range Weather Forecast) ERAInterim dataset (Dee et al., 2011), on a $1^{\circ}$ longitude-latitude grid and 60 vertical hybrid levels (Legras et al., 2005).

For each SVC detected by CALIOP and meeting the criteria from Sect. 2, a Cartesian domain was defined bounded 

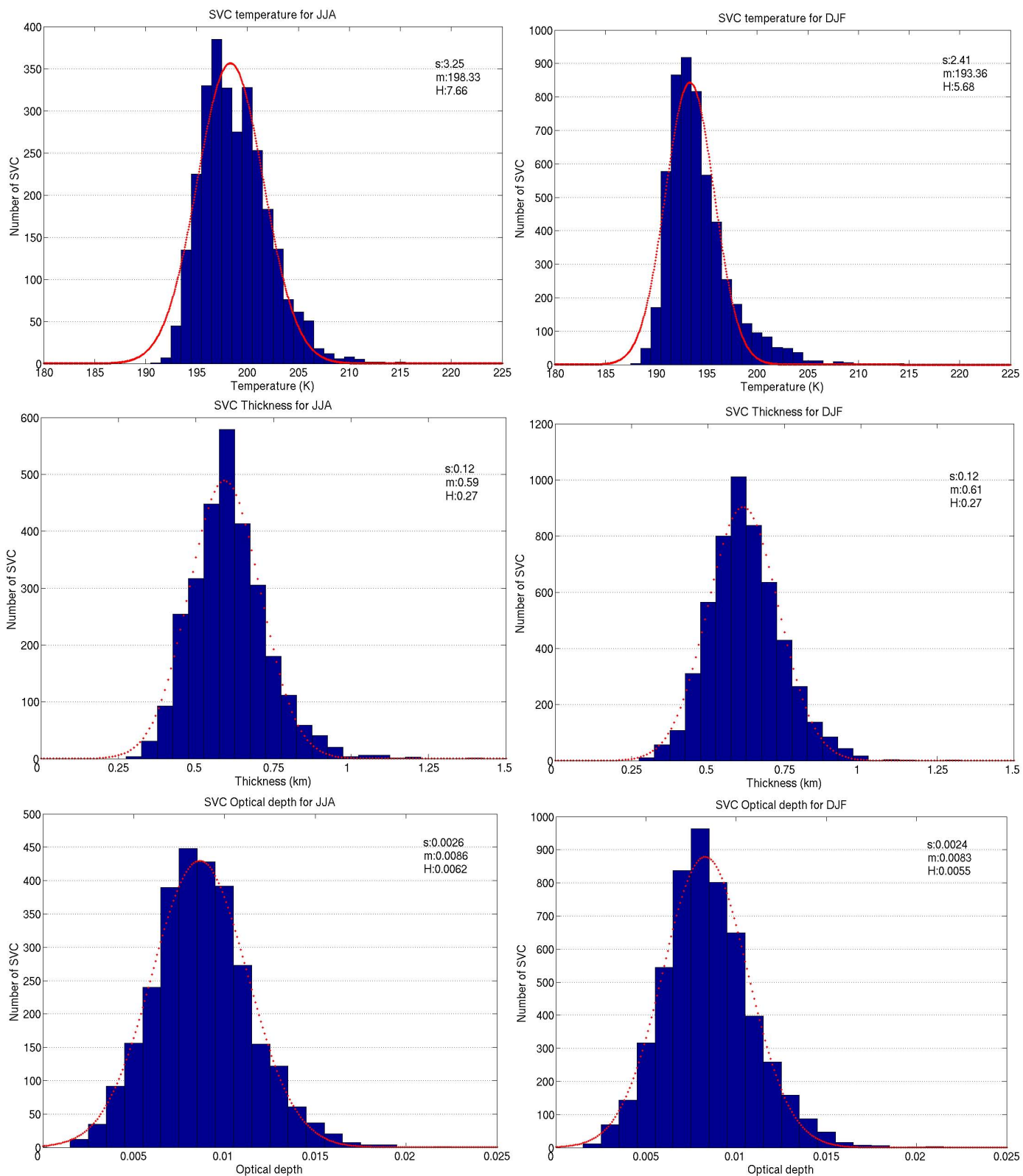

Fig. 2. Histograms of average temperature (row 1), geometrical (row 2) and optical thickness (row 3) for SVC in JJA (left column) and DJF (right), 2006-2008. The mean thickness of SVC is roughly equal to $600 \mathrm{~m}$ and the mean extension to $450 \mathrm{~km}$.

by the cloud beginning and end coordinates in the corresponding CALIOP orbit. This domain was then discretized in $1^{\circ} \times 1^{\circ}$ boxes. In the regions under study, this means dividing each SVC in roughly $100-\mathrm{km}$ sections along-track. The TRACZILLA model released particles in each box center at the mean SVC altitude within the box, and followed their back-trajectories 15 days prior with a 1-h sampling (360 points). Thus, multiple back-trajectories were calculated for each SVC according to its horizontal extent. On average, ten back-trajectories were launched per SVC, although this number exceeded 100 for clouds several thousand kilometers long.

Back-trajectories form different patterns depending on their starting point. Figure 4 displays three representative examples of 15-days back-trajectories in JJA, initialized at the time and place of SVC (dots on Fig. 4). For the SVC detected over South Asia on 11 June 2007 (red), back-trajectories follow a round shape that is typical for initialization over this region. By contrast, an SVC detected over Central America on 31 July 2007 (blue) leads to straight paths that do not deviate much from the SVC latitude. This is typical behavior 

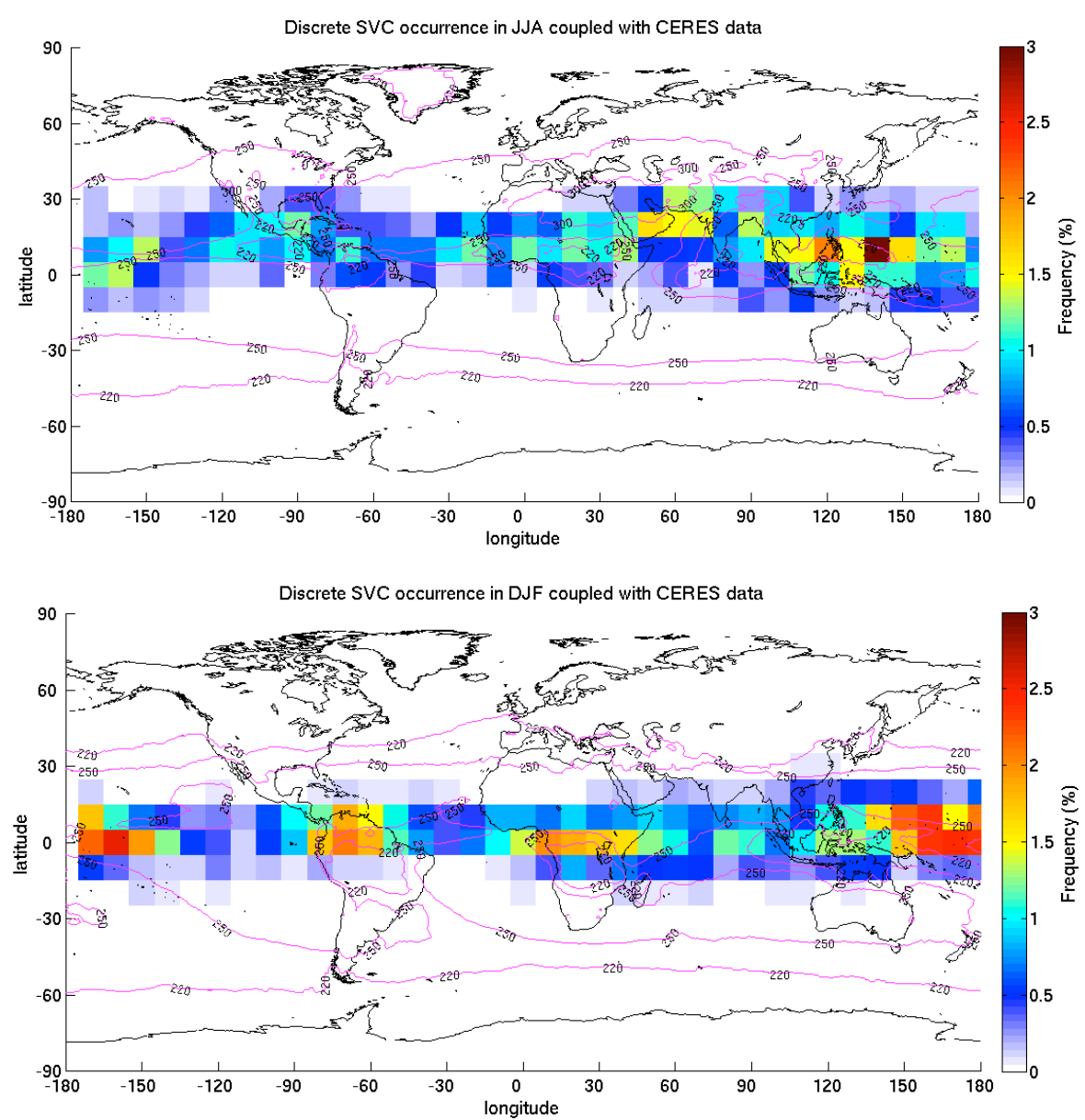

Fig. 3. Geographic distribution of SVC (in \%) for JJA periods (top) and DJF (bottom) for 2006-2008. The sum of all boxes is $100 \%$. Contour lines show top of the atmosphere outgoing longwave flux $\left(\mathrm{W} \mathrm{m}^{-2}\right)$ from CERES monthly means (EBAF product), averaged over the same periods.

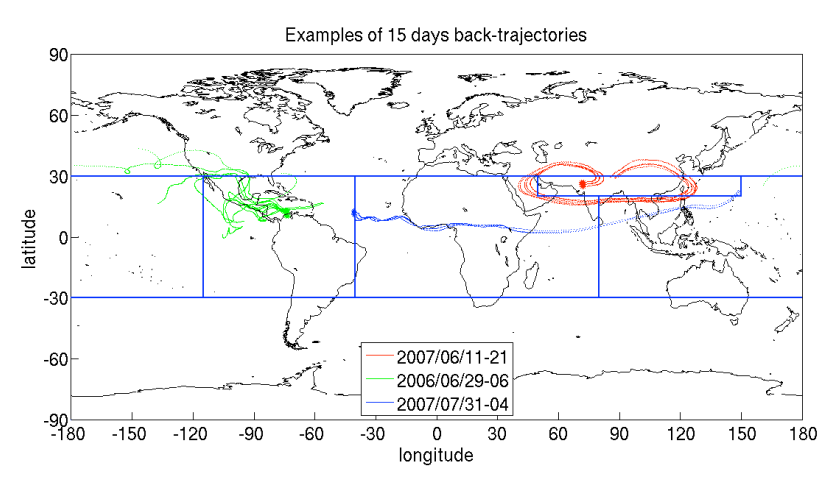

Fig. 4. Examples of three 15-days back-trajectories. For each, dots identify the position of the SVC used to initiate back-trajectory seeding. for back-trajectories initialized near the equator, which typically extend over much longer ranges. A last back-trajectory, associated with an SVC observed over Central America on 29 June 2006, shows a more complex shape (green). In our results, back-trajectories initialized far from the equator generally tend to spread out more.

\subsection{Temperature history coherence}

Back-trajectories initialized in the same vicinity tend to separate over time due to the chaotic properties of advection in a time-varying flow. For instance, the green back-trajectories in Fig. 4 initially originate from nearby sections of the same SVC, but drift apart significantly as time goes back. Due to natural air mass dispersion, the distance between them can reach several degrees, and they eventually spread over the whole tropical belt (Tzella and Legras, 2011). As backtrajectories drift apart, the histories of the air masses they track start to diverge, mixing becomes significant and it gets harder to identify the mechanisms responsible for the 
Table 1. Regions used in the study.

\begin{tabular}{lll}
\hline Region & Latitude range & Longitude range \\
\hline Asia & $30^{\circ} \mathrm{S}-20^{\circ} \mathrm{N}$ & $80-150^{\circ} \mathrm{E}$ \\
$30^{\circ} \mathrm{S}-30^{\circ} \mathrm{N}$ & $150-180^{\circ} \mathrm{E}$ \\
Asian Monsoon & $20-30^{\circ} \mathrm{N}$ & $50^{\circ} \mathrm{W}-150^{\circ} \mathrm{E}$ \\
Anticyclone (AMA) & & \\
Pacific & $30^{\circ} \mathrm{S}-30^{\circ} \mathrm{N}$ & $180-115^{\circ} \mathrm{W}$ \\
Central America & $30^{\circ} \mathrm{S}-30^{\circ} \mathrm{N}$ & $115-40^{\circ} \mathrm{W}$ \\
Africa & $30^{\circ} \mathrm{S}-30^{\circ} \mathrm{N}$ & $40^{\circ} \mathrm{W}-50^{\circ} \mathrm{E}$ \\
& $30^{\circ} \mathrm{S}-20^{\circ} \mathrm{N}$ & $50-80^{\circ} \mathrm{E}$ \\
\hline
\end{tabular}

eventual SVC formation. In order to avoid the complexities linked to the tracking of air masses mixing, we constrained our study to SVC coming from an identifiable air mass. Since temperature is a major factor in ice nucleation processes, we used its variance history to quantify back-trajectories dispersion. For an SVC with n back-trajectories, we computed for each of the 360 time points the temperature variance among the $\mathrm{n}$ back-trajectories. The resulting temperature variance time series was then averaged over 5,10 and 15-days windows back in time. A small temperature variance means that all back-trajectories can be considered to share a common history during the time window. Conversely, large temperature variances are a sign of dispersion, i.e. the histories of the $\mathrm{n}$ back-trajectories diverge significantly.

Figure 5a shows the distribution of temperature variances among 15 days back-trajectories for all SVCs. Backtrajectories with temperature variance below $4 \mathrm{~K}$ were classified as "coherent 1" $(\mathrm{C} 1)$, temperature variance between 4 and $8 \mathrm{~K}$ as "coherent 2" (C2) and temperature variance above $8 \mathrm{~K}$ as "divergent" (D). Figure $5 \mathrm{~b}$ and c show examples of temperature histories and how the associated SVC was classified according to the criterion explained above. Figure $5 \mathrm{~b}$ shows a case with roughly constant temperature (around $-75^{\circ}$ ) for all back-trajectories. This SVC was categorized as $\mathrm{C} 1$ at 5, 10 and 15 days back in time. Figure $5 \mathrm{c}$ shows a case in which the temperature decreases significantly during the first 5 days back in time, but temperature variance stays low. As time goes back, temperature variance increases, a sign of history divergence among back-trajectories. This SVC was characterized as $\mathrm{C} 1$ considering only the 5 days preceding its observation, but $\mathrm{D}$ considering 10 and 15 days.

We studied SVC temperature history coherence in 5 geographical areas described in Table 1 and shown in Fig. 4, similar to those used by Riihimaki and McFarlane (2010). Asia and Africa regions are truncated to accommodate the Asian Monsoon Anticyclone region (AMA), a special case due to its specific meteorology. Numbers of SVC classified based on their temperature history over 15 days are presented by region in Table 2 for JJA (top) and DJF (bottom). In Fig. 6 Asia, Africa and Central America stand out again as SVC hotspots (as in Fig. 3). Temperature coherence does not change much
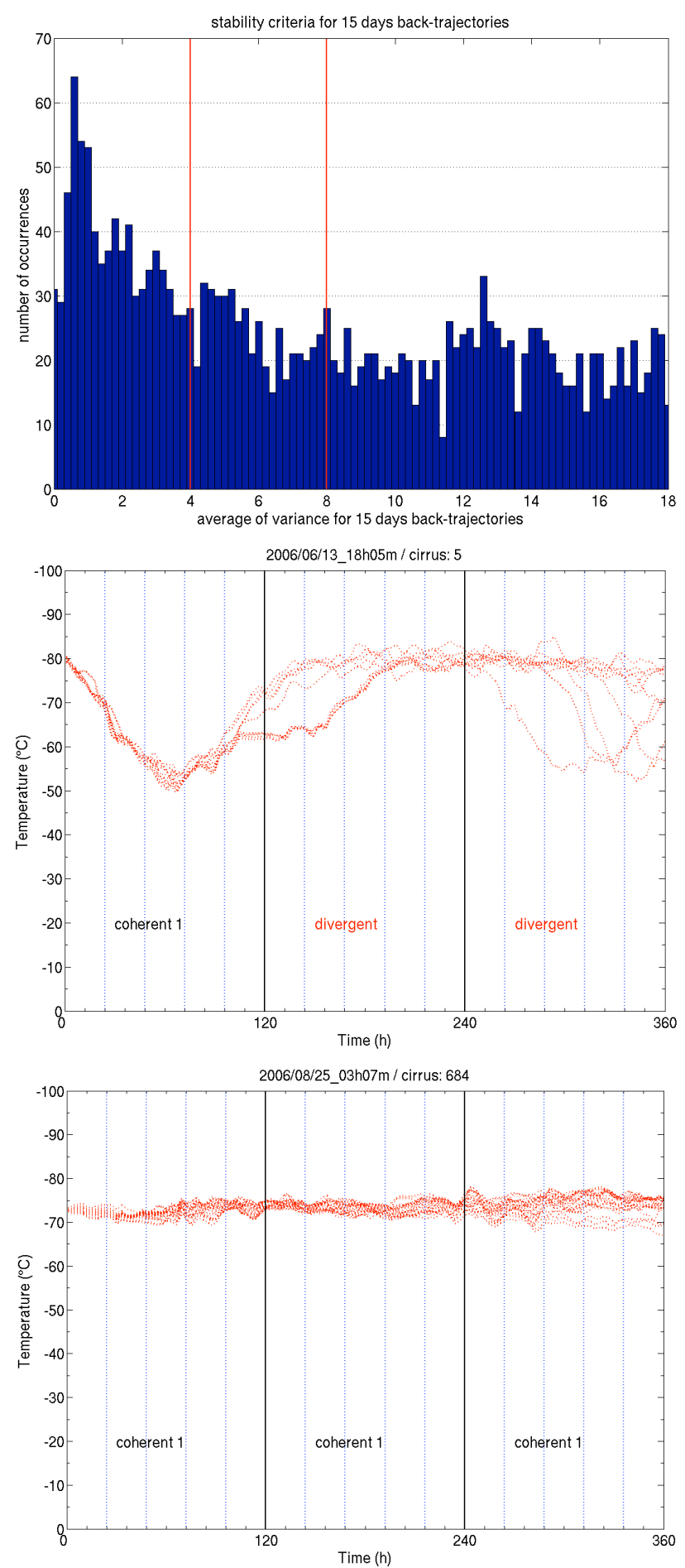

Fig. 5. (a) Histogram of temperature variance for 15 days backtrajectories for each SVC over $3 \mathrm{yr}$ of data. Red lines represent the 3 different classifications. (b, c) Example of temperature histories across 15-days. The temperature coherence criterion is applied on 5-days windows. 
Table 2. Number of SVC according to their temperature history coherence in DJF and JJA (from 2006 to 2008) over 15 days back-trajectories.

\begin{tabular}{lrrrrrr}
\hline JJA & Africa & Asia & AMA & Central Am. & Pacific & Total \\
\hline C1 & 117 & 61 & 24 & 71 & 59 & $332(11.8 \%)$ \\
C2 & 69 & 48 & 27 & 40 & 28 & $212(7.5 \%)$ \\
D & 590 & 891 & 198 & 307 & 280 & $2266(80.6 \%)$ \\
Total & $776(27.6 \%)$ & $1000(35.6 \%)$ & $249(8.9 \%)$ & $418(14.9 \%)$ & $367(13.1 \%)$ & 2810 \\
\hline DJF & Africa & Asia & AMA & Central Am. & Pacific & Total \\
\hline C1 & 196 & 81 & 6 & 85 & 44 & $412(10.2 \%)$ \\
C2 & 108 & 80 & 2 & 40 & 36 & $266(6.6 \%)$ \\
D & 894 & 1305 & 32 & 579 & 551 & $3361(83.2 \%)$ \\
Total & $1198(29.7 \%)$ & $1466(36.3 \%)$ & $40(1 \%)$ & $704(17.4 \%)$ & $631(15.6 \%)$ & 4039 \\
\hline
\end{tabular}
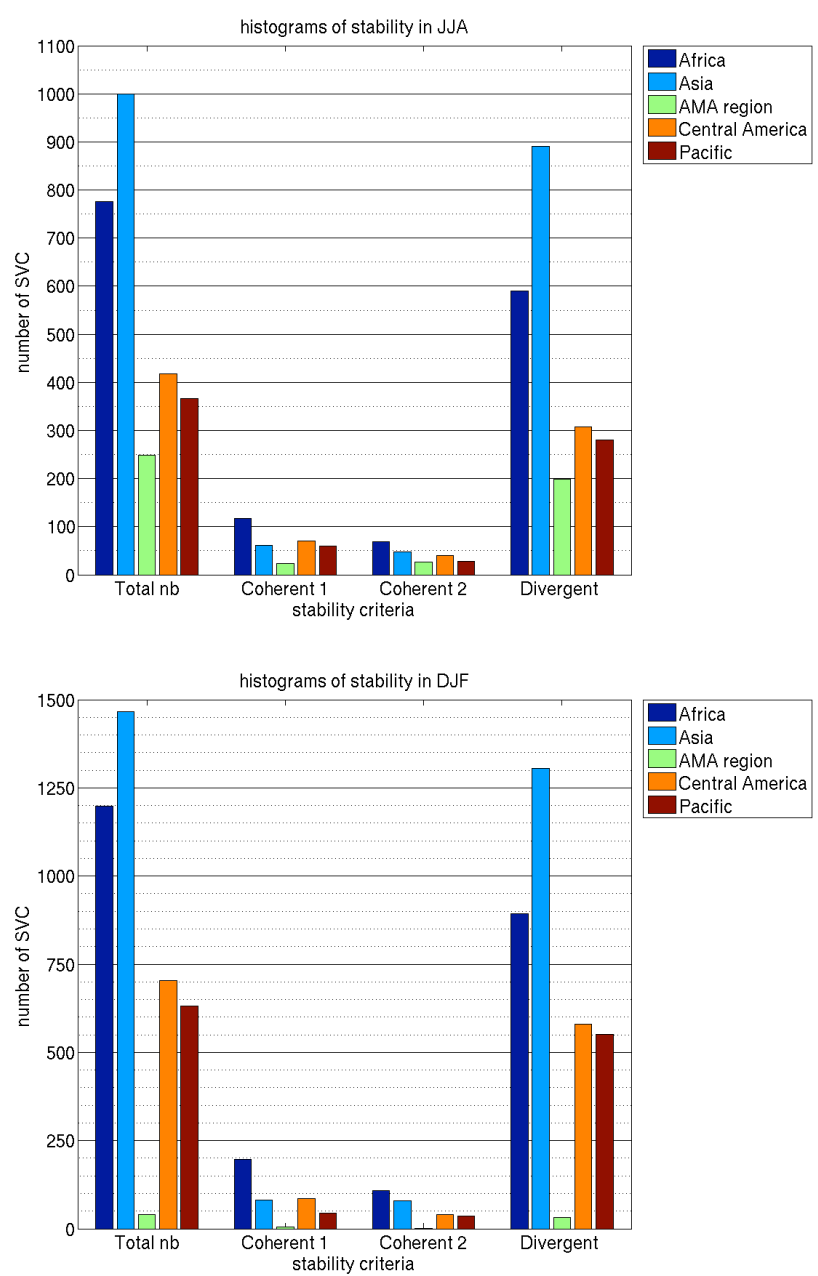

Fig. 6. Histograms of SVC temperature history coherence in JJA (top) and DJF (bottom) by area.

between winter and summer, except over the AMA region where it almost vanishes during winter. Over 10 days (not shown), the number of $\mathrm{C} 1 \mathrm{SVC}$ is more than double $(\sim 25 \%)$ than over 15 days $(11.8 \%)$, while the number of C2 SVC increases slightly ( $\sim 12 \%$, compared to $7.5 \%$ over 15 days). Over 5 days, the number of $\mathrm{C} 1 \mathrm{SVC}$ more than doubles again ( $\sim 58 \%$ ) compared to 10 days. We understand the C2 state as transitory between $\mathrm{C} 1$ and $\mathrm{D}$ states.

The rest of the paper will focus on C1 SVC with the most coherent temperature history before cloud formation, based on the assumption that it should be easier to identify mechanisms responsible for their formation. 15-days temperature histories are used throughout.

\section{SVC with coherent temperature histories}

\subsection{Geographical distribution and properties of C1 SVC}

Figure 7 shows the geographical distribution of C1 SVC. In DJF, there are noticeably more SVC over the Gulf of Guinea and Africa $(\sim 6 \%)$ and less elsewhere. In JJA, SVC are more scattered, with disputable hotspots over the western Pacific, Central America and West Africa. Geographic distributions of C1 SVC do not necessarily match those of the general SVC population (Fig. 3). Table 3 describes how C1 SVC fall in five temperature ranges. Almost half of C1 SVC (45.4\%) are in the middle $191-195 \mathrm{~K}$ range, $26.5 \%$ in the $188-191 \mathrm{~K}$ range and $17.5 \%$ in the $195-205 \mathrm{~K}$ range. The remaining small number of C1 SVC (10.6\%) are either very cold (183$188 \mathrm{~K})$ or very "warm" (205-215 K). $55.4 \%$ of C1 SVC are detected in DJF and $44.6 \%$ in JJA, which is close to the distribution of the entire SVC population (Sect. 2). According to the Kolmogorov-Smirnov test at a $5 \%$ significance level, C1 SVC have properties very similar to the general SVC population, being on average colder by less than $1 \mathrm{~K}$ and thinner by $80 \mathrm{~m}$ (keeping in mind that CALIOP vertical resolution is $60 \mathrm{~m}$ near the TTL). Their average optical depths are roughly equal.

We calculated the cloud depolarization and color ratios (Sect. 2) for each SVC averaged over its vertical range and horizontal sections used as starting points for backtrajectories (Sect. 3.1). Distributions of depolarization ratio 
Table 3. Number of C1 SVC with respect to temperature. Most SVC are located in 195-191 K.

\begin{tabular}{lrrr|rrrr}
\hline & \multicolumn{3}{c|}{ DJF } & \multicolumn{3}{c}{ JJA } \\
\cline { 2 - 6 }$T\left({ }^{\circ} \mathrm{K}\right)$ & $2006-07$ & $2007-08$ & $2008-09$ & 2006 & 2007 & 2008 & Total \\
\hline $215-205$ & 0 & 0 & 0 & 41 & 0 & 2 & 43 \\
$205-195$ & 21 & 3 & 6 & 20 & 53 & 27 & 130 \\
$195-191$ & 127 & 20 & 27 & 58 & 69 & 37 & 338 \\
$191-188$ & 88 & 60 & 24 & 14 & 8 & 3 & 197 \\
$188-183$ & 13 & 17 & 6 & 0 & 0 & 0 & 36 \\
\hline Total & 249 & 100 & 63 & 133 & 130 & 69 & 744 \\
\hline
\end{tabular}
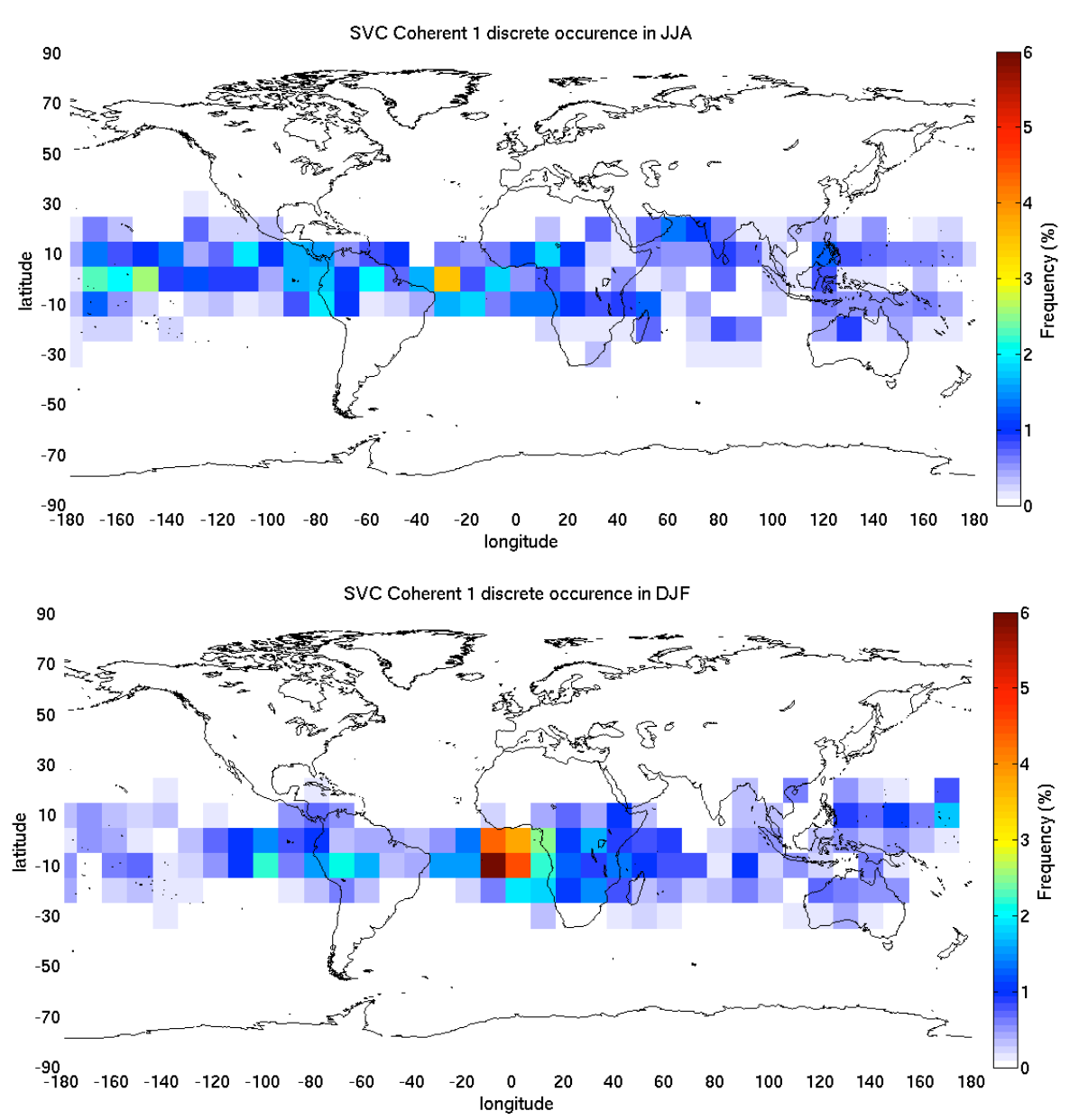

Fig. 7. Distribution of C1 SVC (\% of total population) in JJA (top) and DJF (bottom).

vs. temperature (Fig. 8, top), and of depolarization vs color ratio (Fig. 8, bottom) suggest groups with distinct optical properties. A large group shows large depolarization $(0.3-$ $0.5)$, temperatures near $193 \mathrm{~K}$ and color ratios close to 1 ( $88.6 \%$ of SVC). These properties are consistent with large, non-spherical particles such as ice crystals from typical upper tropospheric clouds (Sassen and Benson, 2001; Chiriaco et al., 2007). A much smaller group at temperatures near $205 \mathrm{~K}$ shows near-zero depolarization ratio and small color ratios (below 0.4), typical of near-spherical small particles (8\% of SVC). Almost all layers belonging to this second group were observed in the low stratosphere during JJA 2006, and were identified by Carn et al. (2007) as sulfate aerosols produced after injection of $\mathrm{SO}_{2}$ in the stratosphere by the eruption of the Soufrière Hills volcano (Montserrat) on 20 May 2006. These layers extended over several thousand kilometers and 

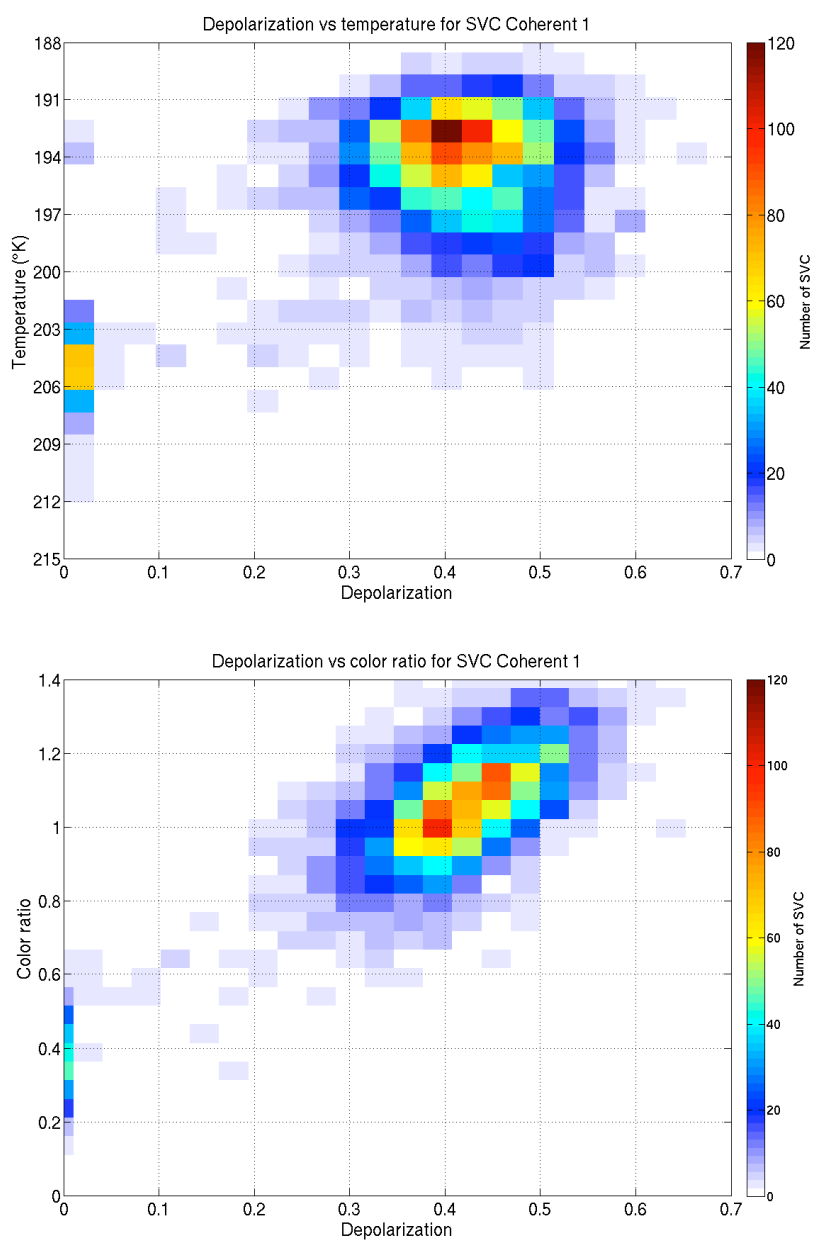

Fig. 8. Distributions of depolarization ratio vs. temperatures (top), and depolarization ratio vs. color ratio (bottom) for all C1 SVC over 15-days in 2006-2009.

dispersed slowly while traveling around the globe for several weeks. We will not consider them as clouds here, as they are purely stratospheric, but will discuss their potential impact on the SVC population in Sect. 5.2.

\subsection{Histories of air masses leading to C1 SVC}

Here we focus on Africa in DJF and the Pacific in JJA, areas with large numbers of C1 SVC detections. Figure 9 shows these detections between 2006 and 2008 (top row), and the spatial distribution of associated 5, 10 and 15-days backtrajectories. For DJF SVC over Africa (left column), most air masses originate from the same area and stay there, with a few coming from Asia and America. Moving back in time from 5 to 15 days, maximum densities gradually shift away from the gulf of Guinea toward the Somali Basin. For JJA SVC observed over Pacific (right column), most air masses originate from the same vicinity, but as time goes back maxima shift to the East and to Central America. At 15 days, the
Atlantic becomes a non-negligible source for air leading to Pacific SVC.

Figure 10 shows histograms of total length travelled by back-trajectories versus the distance reached at their furthest point away from the SVC of origin, for back-trajectories classified as $\mathrm{C} 1$ over 15, 10 and 5 days in JJA Pacific and DJF Africa. The total length exhibits similar range over both regions (up to $\sim 30000 \mathrm{~km}$ ), but distributions differ. Over the Pacific (left column), long trajectories (total lengths $>10000 \mathrm{~km}$, up to $22000 \mathrm{~km}$ ) are as common as short ones, and a minority of extremely long paths reach $35000 \mathrm{~km}$. By contrast, over Africa (right column), short trajectories (5000$12000 \mathrm{~km}$ ) clearly dominate. This is consistent with Fig. 9, which shows longer trajectories being more prevalent over Pacific than over Africa. Over 15 days (top row), 3 groups can be identified over both regions:

1. Short total length $(<12000 \mathrm{~km})$ and much smaller reach. These paths are roughly circular, and do not stray far away from the area of SVC detection (similar to the red path in Fig. 4).

2. Roughly equal total length and reach, close to the identity line $(12000-20000 \mathrm{~km})$. These paths are roughly straight (similar to the blue path in Fig. 4).

3. Long total length $(>20000 \mathrm{~km})$ and relatively short reach. These trajectories have complicated shapes, which are neither circular nor straight.

Shorter time periods (rows 2 and 3) mean back-trajectories travel over shorter distances and have shorter total lengths. As a consequence they are less likely to evolve complicated shapes and the distributions aggregate around the identity line in both regions. Curved trajectories (reach considerably smaller than the total length) still appear in DJF Africa over 10 days (right column). This suggests that trajectories need at least 10 days to evolve a circular shape.

\section{Three candidate processes for SVC formation}

This section investigates the possibility that three atmospheric processes help create the population of C1 SVC identified in Sect. 4: inclusion of nitric acid, nucleation of ice crystals on liquid or solid aerosols, and convection.

\subsection{Inclusion of nitric acid}

The formation of Nitric Acid Trihydrate crystals (NAT) by mixing of water vapor and $\mathrm{HNO}_{3}$ near $195 \mathrm{~K}$ has been observed in the polar stratosphere for more than a decade (Voigt et al., 2000). These crystals can be distinguished from pure ice crystals by their specific optical signatures (e.g. Noel et al., 2008). The possibility of NAT crystals forming in the similarly cold TTL has been suggested by in-situ observations in the subtropics (Popp et al., 2004, 2007; Voigt et al., 

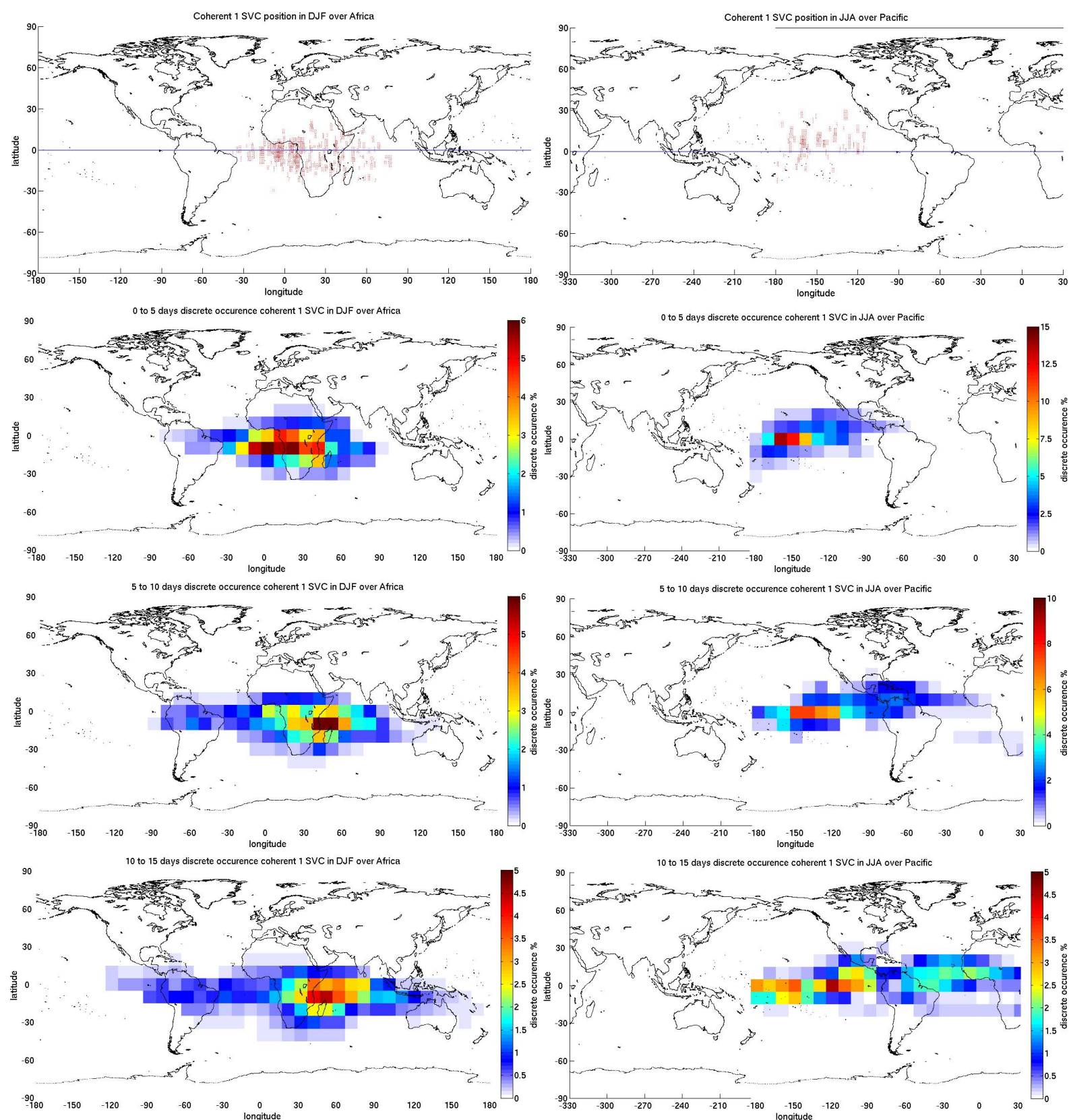

Fig. 9. Top: position of C1 SVC observed over Africa in DJF (left) and Pacific in JJA (right). Second to fourth rows: spatial distribution of C1 back-trajectories over 0-5 days, 5-10 days, 10-15 days.

2007, 2008). The detection of such particles in CALIOP observations is controversial since it is unclear whether the extremely low TTL concentrations of $\mathrm{HNO}_{3}$ can lead to NAT concentrations measurable from space (Poole et al., 2009; Noel and Chepfer, 2009).

As discussed in Chepfer and Noel (2009), such particles would produce intermediate values of depolarization ratio $(0.05-0.25)$ and color ratio (0.4-0.6). Such values make a faint apparition in our dataset (Fig. 8), at temperatures near 200K (3.4\% of C1 SVC). Remote sensing observations alone cannot ascertain the exact nature of the particles under study, but analyzing the temperature history of the air masses leading to SVC formation can provide useful circumstantial evidence to support or infirm the possibility of $\mathrm{HNO}_{3}$ inclusion. For instance, the formation of NAT crystals requires sustained $\mathrm{HNO}_{3}$ supersaturation for long periods (Voigt et al., 2008), as their nucleation process is considerably slower than ice.

Figure 11a shows the total trajectory length vs. the reach away from SVC over 15 days associated with C1 SVC with 

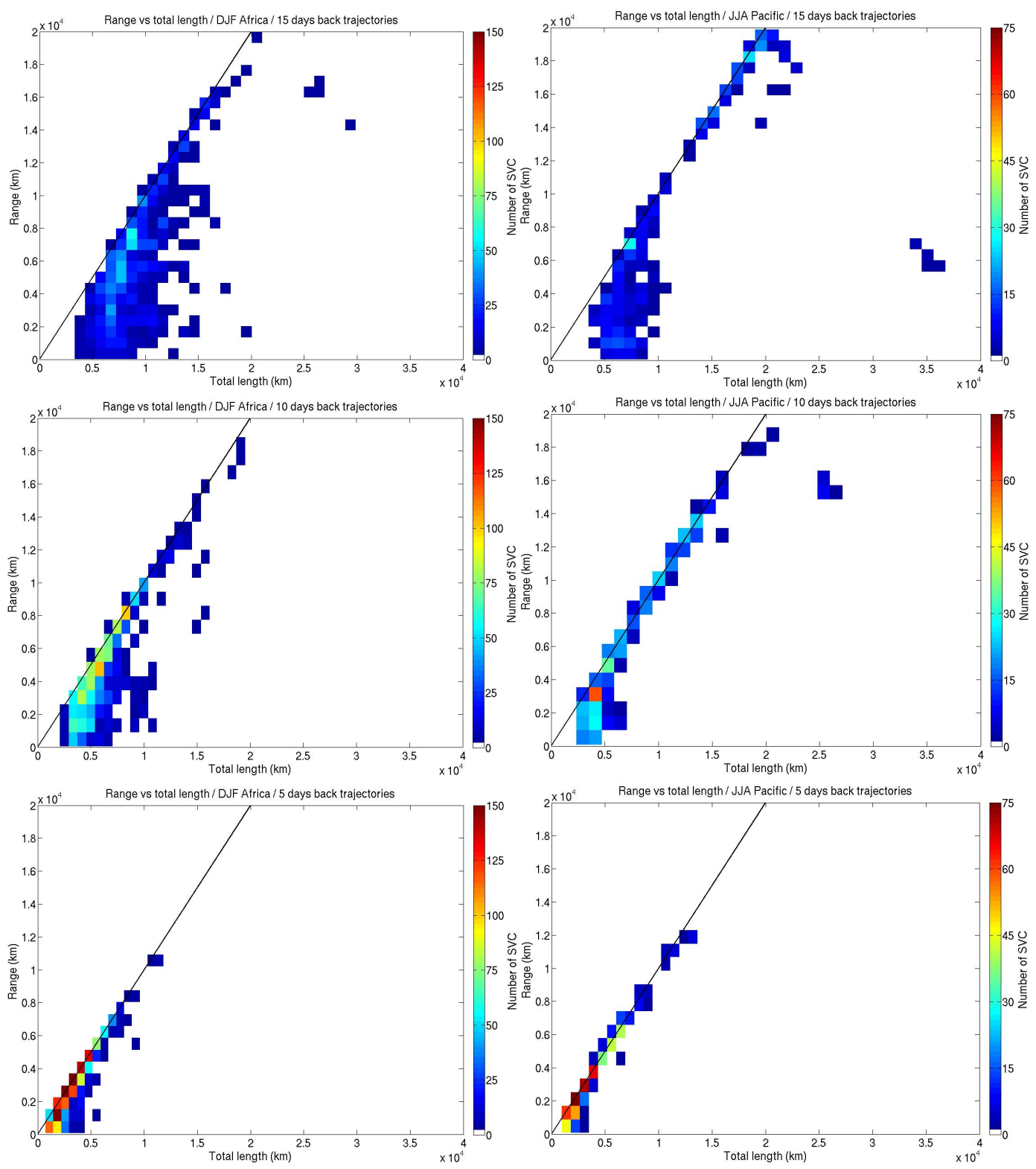

Fig. 10. Histograms of total back-trajectory length (horizontal) vs. reach away from the SVC (vertical) for 15-days (row 1), 10-days (row 2) and 5-days (row 3) C1 back-trajectories over Africa in DJF (left) and over Pacific in JJA (right). The identity line is shown in black.

depolarization ratios in the $0.05-0.25$ range (106 SVC). $30 \%$ of trajectories are nearly straight with large total lengths and reaches $(10000-20000 \mathrm{~km}) .37 \%$ of them deviate from straightness, with total length below $15000 \mathrm{~km}$ and reach below $8000 \mathrm{~km}$. Temperature distribution (Fig. 11b, right) shows a small, cold group (190-197 K, $22 \%$ ), a tall narrow group in the 197-203 K range (34\%) and a warm group $(205-210 \mathrm{~K}, 28 \%)$. This suggests that a relatively large number of $\mathrm{C} 1 \mathrm{SVC}$ with depolarization ratios similar to NAT crystals stem from air masses that travelled along a relatively straight trajectory at stable temperatures colder than $197 \mathrm{~K}$ (56\% of trajectories) over long periods (up to two weeks). Such conditions would physically allow the nucleation of
NAT crystals given adequate $\mathrm{HNO}_{3}$ levels. In any case, only a very small minority $(3.4 \%)$ of $\mathrm{C} 1 \mathrm{SVC}$ is concerned, which themselves form only $\sim 10 \%$ of SVC considering 15-days back-trajectories. Our results thus support the fact that nucleation of NAT-like particles is not a statistically significant process for SVC formation.

\subsection{Local increase in aerosol concentration}

Background aerosols are a potent source of SVC formation (Thomas et al., 2002). There are many possible pathways for ice nucleation from aerosols, whose local importance depends strongly on temperature, mixing ratios of 

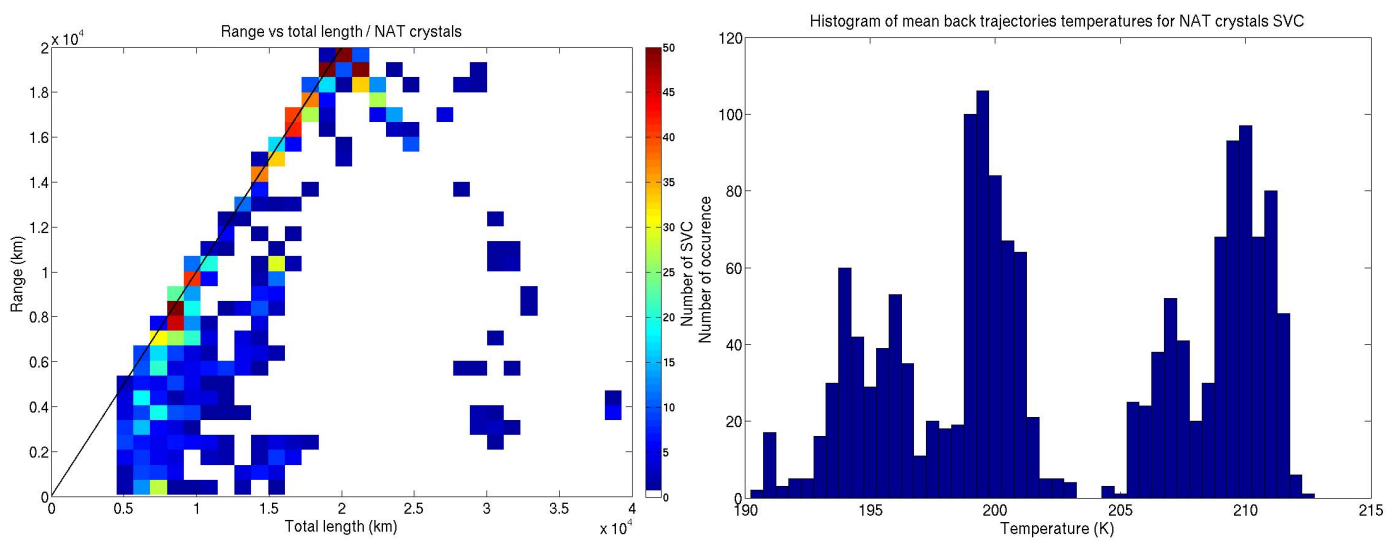

Fig. 11. Distribution of total trajectory length vs. reach away from the SVC (left column) and histograms of mean temperature along the back-trajectory (right column), for C1 SVC with depolarization ratios between 0.05 and 0.25 .

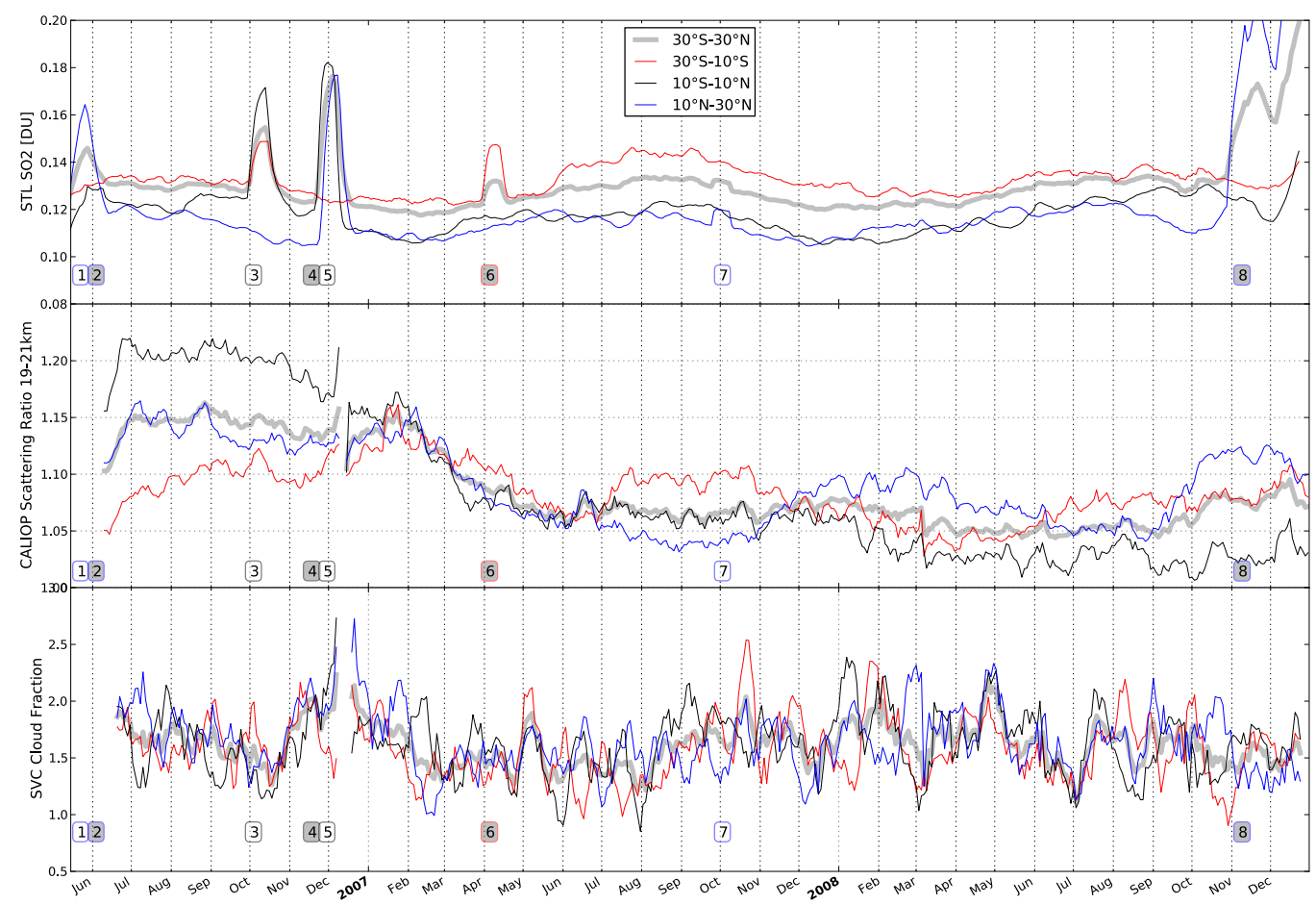

Fig. 12. Top: daily $\mathrm{SO}_{2}$ concentrations observed by OMI (STL data from $\mathrm{OMSO}_{2}$ product v.3). Middle: daily scattering ratios observed by CALIOP between 19 and $21 \mathrm{~km}$ in the same latitude band (CALIOP level 1 data v.3.02). Efforts were made to remove observations affected by the South Atlantic Anomaly. Bottom: daily SVC cloud fraction (percents) from the SEL2 dataset, defined as the number of CALIOP profiles in which SVC were detected on the total number of profiles. The three time series were averaged using a 15-days moving window over the Tropics $\left( \pm 30^{\circ}\right.$, thick grey line) and three equal bands of latitude: $30-10^{\circ} \mathrm{S}$ (red), $10^{\circ} \mathrm{S}-10^{\circ} \mathrm{N}$ (black) and $10-30^{\circ} \mathrm{N}$ (blue). Numbers refer to the eruptions listed in Table 4 and are located on the dates of eruption. The color of their outlines documents the latitude band in which the eruptions occurred, and grey background indicates the eruption failed to reach the TTL.

participating chemical species, aerosol concentrations and size distribution (Lohmann and Diehl, 2006). The active pathway will influence the size and shape of ice crystals in the eventual cloud, and thus indirectly drives its impact on the radiative budget and water vapor redistribution. In the TTL, the possible pathways are somewhat constrained but remain numerous. Background sulfuric acid particles grow by absorbing water vapor at any relative humidity with respect to water, and can subsist as liquid droplets for a long time. Such liquid sulfate aerosols (Jensen et al., 1996) and organic aerosols (Kärcher and Koop, 2005) brought from the surface by convection can freeze either homogeneously or heterogeneously (through interaction with solid aerosols), leading to ice nucleation. Recent research suggests that dry ammonium 
sulfate particles are efficient ice nuclei (Jensen et al., 2010), but other aerosols such as mineral dust and organic carbon (Kärcher, 2002) can also play this role. Due to this complexity, the dominant formation processes of in-situ ice clouds in the TTL has still not been asserted with certainty (Froyd et al., 2010), although the importance of anthropogenic emissions seems notable (Weigel et al., 2011). Because it would be too complex to identify the ice nucleation pathway of each SVC in our dataset, we tried instead to detect a correlation between SVC cover and local increase in the atmospheric concentrations of certain species due to specific events that provide sources of ice nuclei.

\subsubsection{Aerosol increase due to volcanic eruptions}

We first investigate increases in concentration of sulfatebased aerosols and dust that follow volcanic degassing and eruptions (Lohmann et al., 2003; Bingemer et al., 2012). Were such aerosols to play a significant role in the formation of the observed SVC population, an increase in sulfate levels would lead to an increase in the total ice particle number and a shift of their size distribution towards smaller crystals. Such changes would register as an increase in SVC cloud cover measured by CALIOP. The top row in Fig. 12 shows time series of column-integrated $\mathrm{SO}_{2}$ observed by the Ozone Monitoring Instrument (OMI) in the Upper Troposphere/Lower Stratosphere (UTLS) between 15 and $20 \mathrm{~km}$. Using these observations and information from the literature, we identified eight eruptions that could have a potential impact on the TTL levels of aerosol concentrations (Table 4, numbers in Fig. 12), either from direct injection during the eruption or from emissions in the free troposphere lofted to the TTL through convection. The eruption of the Soufrière Hills stratovolcano (1), even though it was modest in terms of stratospheric $\mathrm{SO}_{2}$ loading $(0.1 \mathrm{Tg}$, Prata et al., 2007), had probably the biggest influence on the UTLS composition during that period (Vernier et al., 2011a). The rest of 2006 saw four more eruptions: the strong Tavurvur/Rabaul (3) and Nyamuragira (5) eruptions (the former leading to important spikes in UTLS $\mathrm{SO}_{2}$, see e.g. Clerbaux et al., 2008), and the smaller Hawaii (2) and Nyiragongo (4) eruptions that did not reach the TTL (Yang et al., 2007) and do not register on Fig. 12. In 2007 the Piton de la Fournaise eruption (6), which did not reach the UTLS, and the Jabal El-Tair eruption (7) led to limited increases in UTLS SO 2 , confined to a single latitude band. 2008 saw several important eruptions, including the Chaiten, but most occurred at high latitudes and failed to reach the Tropical band (see e.g. Theys et al., 2009 and Karagulian et al., 2010 documenting the trajectory of the plume from the August 2008 Kasatochi eruption in Alaska). So far we have no explanation for the strong increase in UTLS $\mathrm{SO}_{2}$ shown in Fig. 12 after November 2008, the Dalafilla eruption (8) in November being arguably too weak to even reach the TTL.
Table 4. Eruptions considered in the study.

\begin{tabular}{lllll}
\hline$\#$ & Volcano & $\begin{array}{l}\text { Eruption } \\
\text { date }\end{array}$ & Latitude & $\begin{array}{l}\text { reached } \\
\text { UTLS }\end{array}$ \\
\hline 1 & Soufriere Hills & $2006-05$ & $16.7^{\circ} \mathrm{N}$ & yes \\
2 & Hawaii & $2006-06$ & $20^{\circ} \mathrm{N}$ & no \\
3 & Tavurvur/Rabaul & $2006-10$ & $4^{\circ} \mathrm{S}$ & yes \\
4 & Nyiragongo & $2006-11$ & $1^{\circ} \mathrm{S}$ & no \\
5 & Nyamuragira & $2006-11$ & $1.2^{\circ} \mathrm{S}$ & no \\
6 & Piton de la Fournaise & $2007-04$ & $21.1^{\circ} \mathrm{S}$ & no \\
7 & Jabal El-Tair & $2007-09$ & $15.5^{\circ} \mathrm{N}$ & yes \\
8 & Dalafilla & $2008-11$ & $13.8^{\circ} \mathrm{N}$ & no \\
\hline
\end{tabular}

The middle row of Fig. 12 shows the coincident daily evolution in the same latitude bands of scattering ratio observed by CALIOP between 19 and $21 \mathrm{~km}$ of altitude. This ratio between the particulate and molecular backscatter can be used as a proxy for concentration levels of UTLS aerosols (as in Vernier et al., 2011a). According to these time series, aerosol concentration are initially high, probably due to the layer of sulfate-based aerosols created by the Soufriere Hills eruption in May 2006 that was visible for several weeks in CALIOP stratospheric observations (Carn et al., 2007). SR levels remain high until the end of 2006, probably sustained by $\mathrm{SO}_{2}$ from the Tavurvur/Rabaul and Nyamuragira eruptions. The SR peak in mid-December, in the wake of the Nyamuragira eruption, could be due to instrumental artifacts that affected CALIOP observations during the first two weeks of December 2006. $\mathrm{SO}_{2}$ peaks (top) do not appear instantaneously correlated to scattering ratios (middle), as the conversion of $\mathrm{SO}_{2}$ to sulfate-based aerosols might require the appropriate thermodynamic conditions. Later eruptions (2007 and 2008) do not seem to affect significantly the levels of UTLS aerosol concentrations. Between February and June 2007 scattering ratios decrease uniformly in the Tropics, as aerosols are slowly lofted to higher altitudes and latitudes, before settling on slightly large values in the south Tropics $(\sim 1.1$, red line) and lower values in the north Tropics ( $\sim 1.05$, blue line). The situation gets reversed in December 2007 until June 2008. The end of the period sees a slight increase in scattering ratios in the north and south Tropics, while values keep decreasing along the equator (black line). We intend to further explore those fluctuations in future studies, focusing for instance on any possible residual aerosol presence in the 30$34 \mathrm{~km}$ altitude range that could bias molecular calibration and affect the SR time series shown in Fig. 12.

The bottom row of Fig. 12 shows how the SVC cloud fraction evolves with time in the same latitude bands. Overall, there is no clear correlation with either UTLS levels of $\mathrm{SO}_{2}$ or aerosol concentrations, except for a noticeable increase in SVC cloud fraction coincident with the Nyamuragira eruption (5) in December 2006. During that period, SVC cloud fraction reaches $3 \%$, almost double its value in the same period in 2007 and 2008. It is however unclear at this 
point if this increase in cloud fraction is not due to sections of the Nyamuragira volcanic plume being misclassified as SVC in CALIOP observations. Plumes can arguable contain solid, non-spherical particles that are harder to single out in CALIOP detections than liquid-based sulfate aerosols (as in Sect. 5.1). Smaller spikes in SVC south Tropics cloud fraction (up to $2.5 \%$ ) appear in May and October 2007 and are quite close to the Piton de la Fournaise and Jabal El-Tair eruptions. However, the latter erupted in a different latitude band (Vernier et al., 2011b) for which no SVC increase can be seen, so it is hard to draw any firm conclusion. Correlation coefficients are fittingly low (0.12 and 0.14$)$.

\subsubsection{Asian Monsoon aerosol increase}

Unrelated to volcanic eruptions and biomass burning, Vernier et al. (2011c) used CALIOP observations to identify a seasonal enhancement of the background sulfate aerosol concentration in the upper troposphere (13-18 km altitude range) every year between June and August in the area under the influence of the Asian Monsoon $\left(15-45^{\circ} \mathrm{N}, 5-105^{\circ} \mathrm{E}\right)$. This area is part of the tropical band we are interested in $\left( \pm 30^{\circ}\right)$. Figure 13 shows the SVC cloud fraction in this area (green line) fluctuates considerably (probably due to the smaller sample size), but is on average equal to the one over the whole tropical band ( $\sim 1.6 \%$ for both). It is indeed higher than average from June to August 2006, a pattern that however does not repeat in 2007 or 2008. Such a seasonal influence would however be difficult to separate from the effects of the convective activity cycle itself.

\subsubsection{Aerosol increase from biomass burning}

Biomass burning events (see e.g. Spichtinger et al., 2001) are frequent over Africa and Madagascar, and produce hygroscopic organic aerosols that can act as ice nuclei (Petters et al., 2009). To investigate the importance of such aerosols on SVC formation, we used carbon monoxyde measured from the Microwave Limb Sounder (MLS) in the UTLS (140$215 \mathrm{hPa}$ ) as a proxy for biomass burning intensity (Filipiak et al., 2005). Figure 13 presents daily CO concentrations averaged using a 15-days window over the entire period under study in the same latitude bands as in Fig. 12. These time series show a seasonal evolution of $\mathrm{CO}$, with both hemispheres in opposition: maxima occur between June and September in the north Tropics, and between October to January in the south Tropics. They are related to the spring increase in biomass followed by summer high temperatures, which increase the risk of fires (Folkins et al., 2006). This cyclical evolution is not apparent in the SVC cloud fraction shown in Fig. 12 (bottom), whose fluctuations cannot be reconciled with the carbon monoxyde UTLS evolution. Accordingly, the correlation coefficient between both time series is 0.09 , which effectively rules out any connection between both phenomena.

\subsection{Convective activity}

Detrainment from cloud systems generated by deep convection is important for SVC formation (see e.g. Jensen et al., 1996). For instance, tropical cumulonimbus can generate extensive cirrus outflow anvils from which larger crystals precipitate, leaving behind optically thin layers of small ice crystals. Isolated ice clouds can also form in-situ from humid air brought to high altitudes by convection and lofted above $15 \mathrm{~km}$ towards and across the cold point of the tropical tropopause by the mean clear air ascent (Fueglistaler et al., 2009).

Here we investigate whether C1 SVC can be linked to convective systems, identified as cold areas in maps of brightness temperature (BT) indicative of optically thick high altitude clouds (Arnaud et al., 1992), against the warm background of surface emissions. In order to get global coverage, we used the MERG dataset from the Climate Prediction Center (Janowiak et al., 2001). This dataset merges measurements from five geostationary satellites (GOES-8/10, METEOSAT$7 / 5$ and GMS) and maps BT globally with a $\sim 4 \mathrm{~km}$ resolution between $60^{\circ} \mathrm{S}$ and $60^{\circ} \mathrm{N}$ hourly since February 2000 .

We extracted BT $20 \mathrm{~km}$ around each point along each back-trajectory of each C1 SVC from the MERG map closest in time to the point (less than 30 min apart). We compared the coldest BT in this area with the temperature retrieved at the back-trajectory point altitude, estimated by TRACZILLA from the ECMWF input field. When both temperatures are cold, the air mass tracked by the back-trajectory travelled near the top of a high-altitude convective system. As an example, Fig. 15 shows brightness temperatures composited from multiple MERG maps covering 15-days trajectories originating from a SVC observed over the Atlantic on 13 June $2006\left(\sim 25^{\circ} \mathrm{W}, 0-5^{\circ} \mathrm{N}\right)$, back-propagating East to $\sim 110^{\circ} \mathrm{E}$ and circling back. Most of the BT are warmer than $280 \mathrm{~K}$ (red) and denote clear-sky conditions. During the same period, the air masses tracked by the back-trajectories stay colder than $220 \mathrm{~K}$ (Fig. 16, red). This means the air mass often travelled high above low-level clouds or the surface. Cold BT (180-200 K) appear 80-100 h and $\sim 340 \mathrm{~h}$ before SVC detection (Fig. 16, black), in the $5^{\circ} \mathrm{W}-10^{\circ} \mathrm{E}$ area (blue in Fig. 15 near the SVC location), and indicate intersections with high-level convective systems. The difference between BT and back-trajectory temperature is less than $20 \mathrm{~K}$ in these periods and areas, symptomatic of an intersection with a high-altitude cloud system.

We analyzed in the same manner $\sim 7000$ back-trajectories for the 744 C1 SVC that were identified in Sect. 4. These back-trajectories always stayed colder than $220 \mathrm{~K}$, meaning all the tracked air masses travelled high in the upper troposphere over the fifteen days preceding SVC formation. By comparison, surrounding BT are very warm most of the time (close to ground temperature), indicating that air masses mostly travel above areas in clear-sky conditions. For each trajectory, we identified where its temperature got closest 


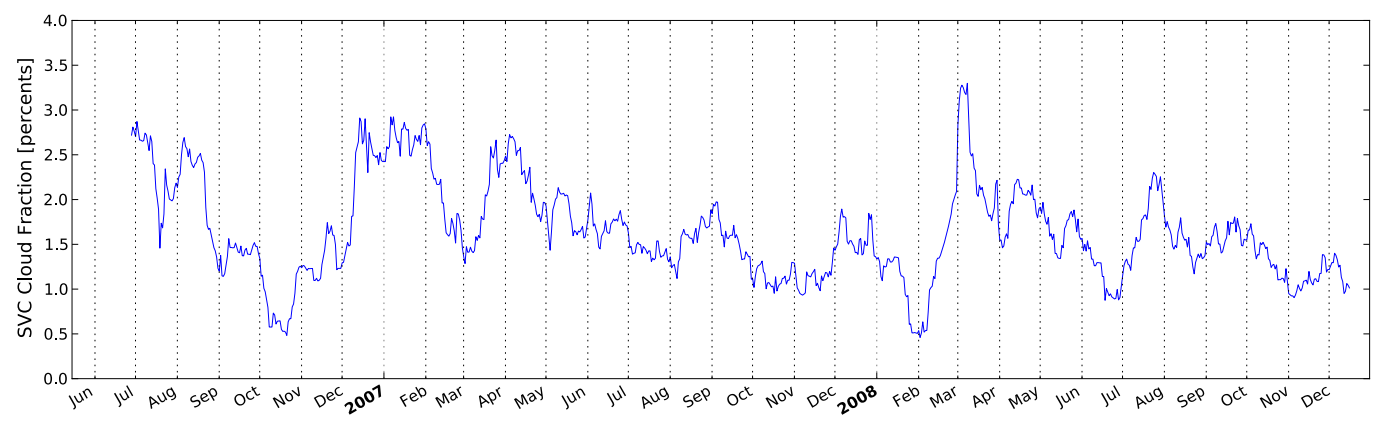

Fig. 13. Average cloud fraction of SVC (defined as in Fig. 12) in the Tropical band in the Monsoon-affected area (see text), averaged using a 31-days moving window to account for the increase in noise due to the smaller sample size compared to Fig. 12.

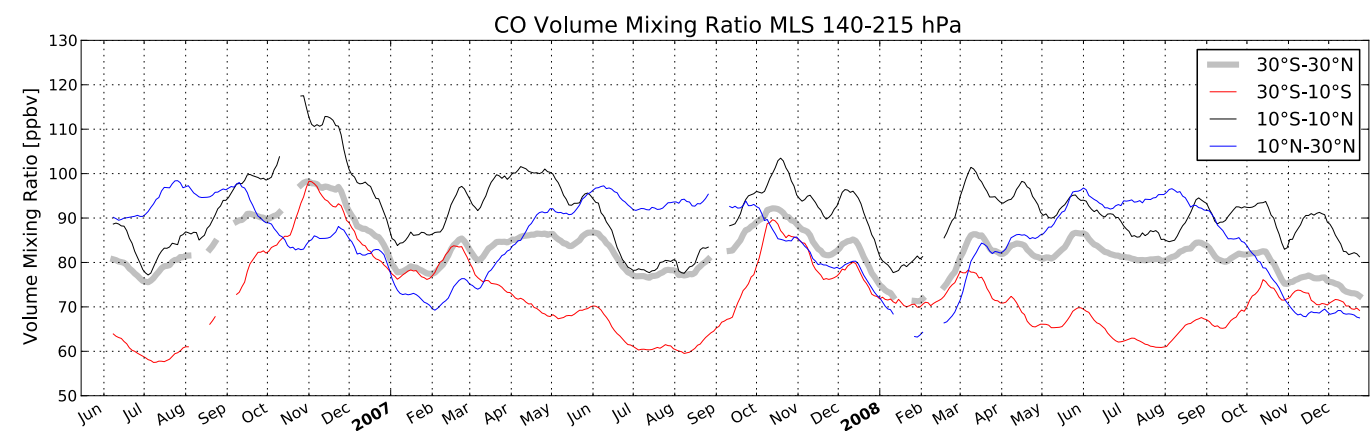

Fig. 14. Daily CO volume mixing ratios observed by MLS (Level 2 CO product v.3) between 140 and 215 hPa, averaged using a 15 -days moving window over the same latitude bands as in Fig. 12.

to its surrounding BT. The minimum temperature difference across all trajectories is distributed between $40 \mathrm{~K}$ and $0 \mathrm{~K}$ (Fig. 17), with a $20 \mathrm{~K}$ difference being most frequent. Table 5 documents how frequent are SVC for which at least one back-trajectory crosses a convective system, meaning the minimum temperature difference was less than $20 \mathrm{~K}$. Over the entire Tropics, this percentage increases from $24.2 \%$ (JJA) and $17.9 \%$ (DJF) over five days to $\sim 60 \%$ over fifteen days, meaning that almost two-thirds of the air masses leading to SVC formation had a close encounter with the top of an optically thick high-altitude cloud system during the previous fifteen days. In that period, those trajectories generally spend less than 24 cumulated hours over convective systems and mostly travel over clear-sky areas. Highest percentages are reached during DJF over Africa $(\sim 79 \%$ of SVC related to convection) and during JJA over Central America $(\sim 83 \%)$. Over the Asia and Pacific regions, SVC are more related to convection in JJA (62\%) than in DJF (37 to $45 \%$ ). Air masses spending more than $24 \mathrm{~h}$ above convective systems over the 5 days exist but are rare (less than $10 \%$ of trajectories). On the other hand, $34 \%$ of back-trajectories always stay more than $40 \mathrm{~K}$ away than their surrounding BT and travelled only over low-level clouds or the surface. Note that cloud top temperatures retrieved through thermal imagery analysis have a warm bias of at least several $\mathrm{K}$, as the ice-based translucent top of convective systems lets warm emissions shine through from lower parts of the cloud (Sherwood et al., 2004). Actual cloud top temperatures are thus probably colder than the reported BT and the numbers reported here are probably underestimates. The points of minimum temperature difference are rare in the first $48 \mathrm{~h}$ preceeding the SVC detection, and are distributed rather homogeneously over time after that (not shown). The proportion of SVC with NAT-like optical properties (Sect. 5.1) stays the same $(5-10 \%)$ regardless if the air mass generating the cloud have interacted with convective activity or not.

Although these results cannot provide direct evidence to document how ice crystals nucleation led to SVC formation, they show that convective events appear in the recent history of 24 to $61 \%$ of $\mathrm{C} 1 \mathrm{SVC}$ during JJA and 18 to $60 \%$ of $\mathrm{C} 1$ SVC during DJF over the 2006-2008 period. Our results suggest the influence of convective activity is slightly stronger in JJA compared to DJF, and is especially noticeable over Africa and Central America.

\section{Summary}

In this study, we first documented on a global scale properties of optically thin layers identified in a previous paper as 


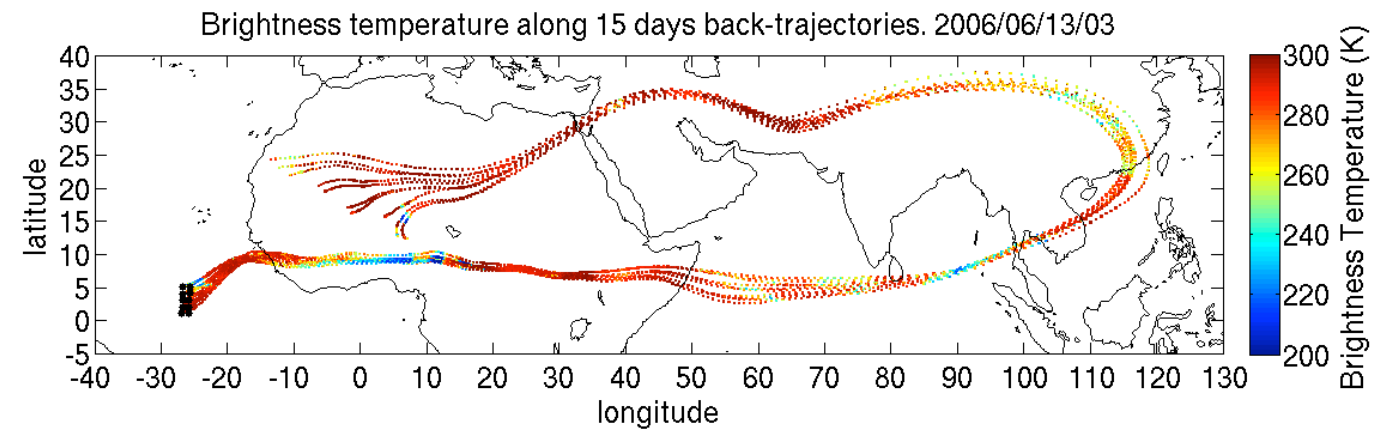

Fig. 15. Brightness temperatures (K) along 10 back-trajectories initialized on 13 June 2006 near 03:15 UTC. SVC detections near $27^{\circ} \mathrm{E}$ are marked by crosses. This composite map was produced by selecting for each back-trajectory point the MERG map closest in time, and extracting brightness temperatures $20 \mathrm{~km}$ around the point.

Table 5. Percentage of C1 SVC for which at least one back-trajectory cross a convective system 5, 10 or 15 days before SVC detection in JJA and DJF. Numbers above the AMA are unreliable given the very small number of SVC observed there.

\begin{tabular}{rlrrrrrr}
\hline & & Africa & Central Am. & Asia & AMA & Pacific & Total \\
\hline \multirow{3}{*}{ JJA } & 5 days & $34.2 \%$ & $46.5 \%$ & $8.2 \%$ & $8.3 \%$ & $23.7 \%$ & $24.2 \%$ \\
& 10 days & $60.7 \%$ & $76.1 \%$ & $44.3 \%$ & $25 \%$ & $54.2 \%$ & $52.1 \%$ \\
& 15 days & $69.2 \%$ & $83.1 \%$ & $62.3 \%$ & $29.2 \%$ & $62.7 \%$ & $61.3 \%$ \\
\hline \multirow{4}{*}{ DJF } & 5 days & $35.7 \%$ & $4.2 \%$ & $4.4 \%$ & $40 \%$ & $5.4 \%$ & $17.9 \%$ \\
& 10 days & $55.3 \%$ & $15.5 \%$ & $23.5 \%$ & $100 \%$ & $16.2 \%$ & $42.1 \%$ \\
& 15 days & $78.6 \%$ & $36.6 \%$ & $45.6 \%$ & $100 \%$ & $37.8 \%$ & $59.7 \%$ \\
\hline
\end{tabular}

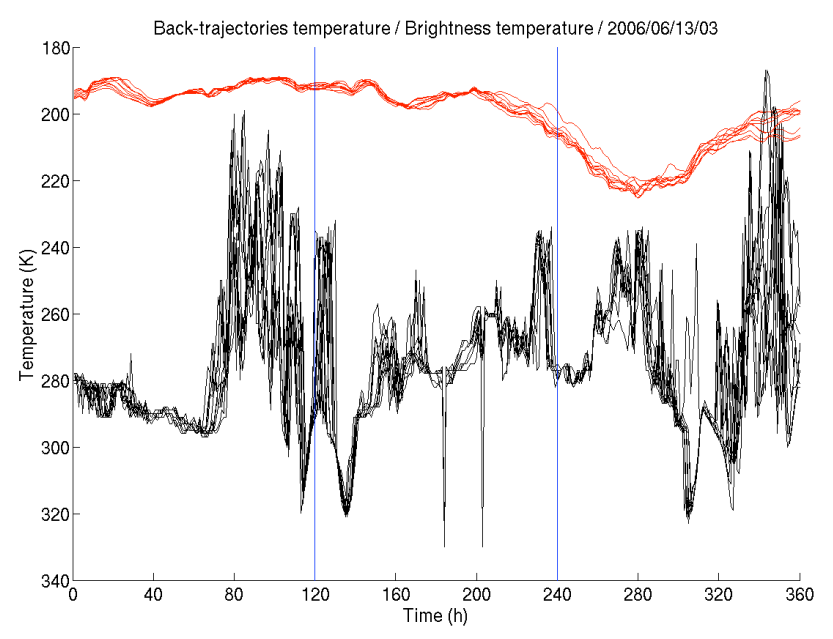

Fig. 16. Evolution of local temperature (red) and coldest brightness temperature from ISCCP (black) along the ten back-trajectories mapped in Fig. 15, as a function of time before SVC detection.

subvisible cirrus in more than $2 \mathrm{yr}$ of CALIOP observations. Most of these layers are $\sim 500 \mathrm{~m}$ thick, colder than $195 \mathrm{~K}$, extremely thin optically (optical depth below 0.015) and a few hundred kilometers wide. We documented the history of air masses that led to the formation of these SVC, using

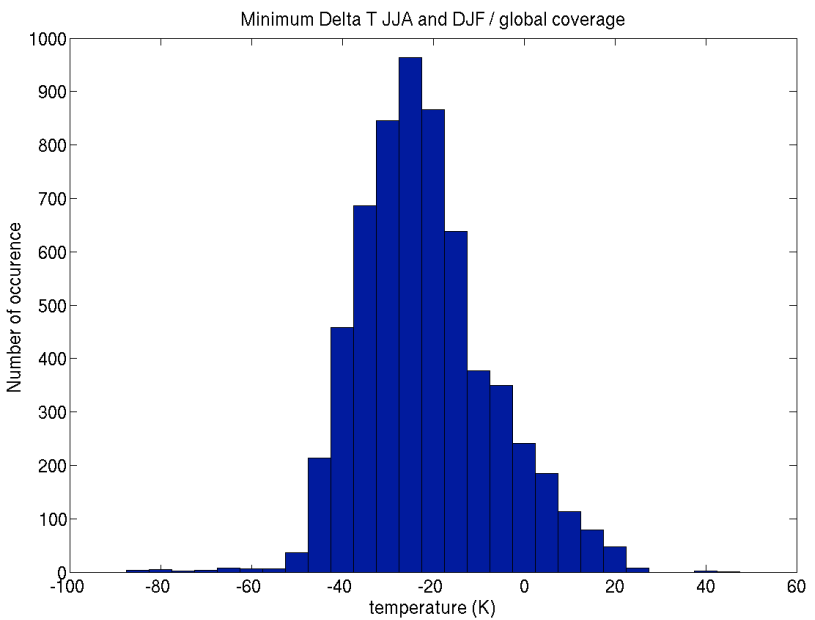

Fig. 17. Distribution of the smallest difference between the temperature at back-trajectory altitude and its surrounding brightness temperature along individual back-trajectories.

back-trajectories from the TRACZILLA model initialized at the location and time of SVC detection. Those air masses travelled equally over Asia, Central America and Africa. The mean latitude of their trajectories is near the equator in DJF while it is near $30^{\circ} \mathrm{N}$ in JJA (close to the AMA region). To 
restrict our analysis to SVC produced by air masses with a clearly identifiable history, back-trajectories were classified based on their temperature history coherence over 5, 10 and 15 days. Most air masses leading to SVC with coherent temperature history observed in DJF Africa originate from Africa or nearby. In the JJA Pacific, more back-trajectories come from Central America and move west across the Pacific.

We studied the importance of three atmospheric phenomena in temperature-coherent back-trajectories over specific regions. Back-trajectories staying for more than 2 weeks in extreme TTL cold $(<205 \mathrm{~K})$, coupled with the analysis of SVC optical properties through depolarization and color ratio, suggest heterogeneous nucleation involving uptake of non-ice species such as $\mathrm{HNO}_{3}$ is a possible formation mechanism for a tiny minority of C1 SVC (3.4\%). The concerned SVC population is so small that this process can hardly be considered statistically significant for optically thin clouds in the TTL. Using spaceborne observations of $\mathrm{SO}_{2}$ and $\mathrm{CO}$ as proxies for the intensity of eruption and biomass burning events, we could only detect a single instance (December 2006) of local increases in the concentration of liquid and solid aerosols having an impact on the SVC cloud cover. Finally, we studied if air masses that led to SVC formation previously intersected convective clouds identified by cold brightness temperatures in a global merged dataset. We found $\sim 20 \%$ of SVC are linked to air masses having interacted with convective activity five days before, and $\sim 60 \%$ over fifteen days. Our main objective in this paper was to establish if processes involving specific ice nuclei or trace species could be a significant influence in the formation of the newly detected SVC population. By showing a strong link between SVC formation and convection, and a comparatively minor influence of the two complementary processes studied $\left(\mathrm{HNO}_{3}\right.$ inclusion and local increases in liquid and hygroscopic aerosols), our results support the idea that the SVC population described in Martins et al. (2011) is to be first and foremost considered as an extension of the more general ice cloud population in the tropical UTLS towards thinner optical depths, and for a large part follow the same formation scenarios as optically thicker clouds.

Convection is the only mechanism that brings significant amounts of water vapor up in the TTL (Corti et al., 2008). It is thus expected that the entirety of water vapor leading to TTL cloud formation originates from a convective system, considering infinite time scales. For instance, Tzella and Legras (2011) followed air masses over 200 days and found that $\sim 80 \%$ of them originate in a convective system, with an average $\sim 27$ days to reach the $370 \mathrm{~K}$ potential temperature level from the surface, although vertical transport times have wide distributions. On shorter time scales, Sassen et al. (2009) and Riihimaki and McFarlane (2010) found 35 to $50 \%$ of ice clouds in the tropical UTLS closely related to convection on near-instantaneous time scales. Through an analysis of CALIPSO cloud water content and MLS wa- ter vapor measurements, Wang and Dessler (2012) found at least $30 \%$ of cirrus in the TTL being of convective origin. They also found this fraction increases as clouds get closer to the cold point tropopause. Our own results are consistent with those above, as we find 20 to $60 \%$ of SVC related to convection, a number that increases with the considered time scales. Over five days, we find globally over the Tropics more SVC associated with convective systems during JJA (24.2\%) than in DJF (17.9\%), consistent with Wang and Dessler (2012). However, over fifteen days this difference disappears ( $\sim 60 \%$ in both seasons) and these results are not homogeneous across the different regions considered. Such results help to assess the significance of different formation hypotheses, e.g. Schwartz and Mace (2010). On the opposite site, by correlating similar CALIOP observations to atmospheric dynamics derived from reanalysis data, Virts et al. (2010) concluded that most TTL cirrus are formed in-situ through temperature drops associated with Kelvin waves in regions of planetary-scale ascent, and that convection is only important for tropical cirrus at lower altitudes $(9-12 \mathrm{~km})$. These results are not necessarily at odds with ours, as both phenomena could simultaneously affect cloud formation. They also remind us of the difficulty to trace cloud formation back to a specific phenomenon, while it requires a combination of several factors (water vapor, temperature, and the availability of ice nuclei), which is not necessarily unique to a specific atmospheric process.

Our results imply that the local increase of water vapor mixing ratio due to convection, or the advection of small ice crystals remaining after anvil precipitation, are significant formation scenarios for a large part of the SVC population. On the other hand, they also imply that at least $40 \%$ of air masses had no interaction with convection fifteen days before they led to SVC formation. These clouds were therefore formed in situ through processes that still need to be identified as the two studied here have insufficient explanatory power. The predominant ice nuclei responsible for SVC formation are not identified yet (Jensen et al., 2001), even if a large body of literature (e.g. Froyd et al., 2010) suggests the homogeneous nucleation of liquid sulfate-based aerosols play an important part. The present study could not adequately link instantaneous changes in SVC cloud fraction to local injections of sulfate aerosols, in the troposphere or stratosphere, either from eruptions or convection. If these aerosols are indeed the primary source of ice nuclei in the UTLS, either (1) the amount of $\mathrm{SO}_{2}$ loading created by the eruptions during the studied period is too small to have any significant impact; (2) the availability of water vapor, and not of ice nuclei, is limiting SVC formation or (3) another unidentified process inhibits water uptake on those aerosols. The activation of nucleation sites by temperature fluctuations due to atmospheric waves (Virts et al., 2010) is another process that might be important for SVC and that needs to be addressed. 
In the near future, we plan to further investigate if the noticeable increase in Tropical SVC cloud fraction in late 2006 can be traced back to the dissipation of the low-stratosphere aerosol layer from the Soufriere Hills. We also plan to combine the back-trajectory approach with case studies of SVC with specific optical properties, to better evaluate the nature of particles composing them, using for example in-situ measurements from the TC4 experiment (Toon et al., 2010). Another avenue of research we intend to explore involves identifying the point of SVC formation along the air mass trajectory. This would require access to the evolution of water vapor mixing ratio and supersaturation levels with time along the trajectory, which could be retrieved for instance from high-resolution water vapor fields out of mesoscale models and/or in-situ observations.

Acknowledgements. The authors would like to thank the IPSL computing and data centers ClimServ and CICLAD for computational facilities, the ICARE thematic center for data access, and the NASA Langley CALIPSO group for producing the CALIPSO data. The authors would like to thank the two anonymous reviewers for useful feedback and suggestions. Funding for part of this work was provided by the ANR project JC07_192911 and CNES.

Edited by: G. Vaughan

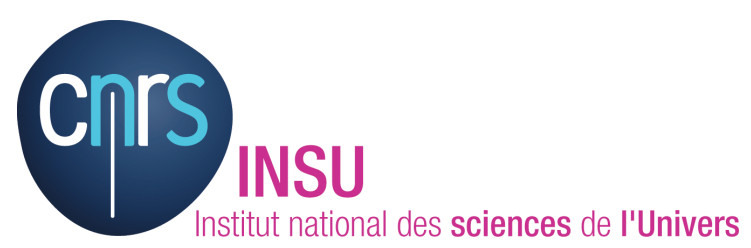

The publication of this article is financed by CNRS-INSU.

\section{References}

Arnaud, Y., Desbois, M., and Maizi, J.: Automatic tracking and characterization of African convective systems on Meteosat pictures, J. Appl. Meteorol., 31, 443-453, 1992.

Bingemer, H., Klein, H., Ebert, M., Haunold, W., Bundke, U., Herrmann, T., Kandler, K., Müller-Ebert, D., Weinbruch, S., Judt, A., Wéber, A., Nillius, B., Ardon-Dryer, K., Levin, Z., and Curtius, J.: Atmospheric ice nuclei in the Eyjafjallajökull volcanic ash plume, Atmos. Chem. Phys., 12, 857-867, doi:10.5194/acp12-857-2012, 2012.

Carn, S. A., Krotkov, N. A., Yang, K., Hoff, R. M., Prata, A. J., Krueger, A. J., Loughlin, S. C., and Levelt, P. F.: Extended observations of volcanic $\mathrm{SO}_{2}$ and sulfate aerosol in the stratosphere, Atmos. Chem. Phys. Discuss., 7, 2857-2871, doi:10.5194/acpd7-2857-2007, 2007.

Chepfer, H. and Noel, V.: A tropical "NAT-like" belt observed from space, Geophys. Res. Lett., 36, L03813, doi:10.1029/2008GL036289, 2009.

Chiriaco, M., Chepfer, H., Minnis, P., Haeffelin, M., Platnick, S., Baumgardner, D., Dubuisson, P., McGill, M., Noël, V., Pelon,
J., Spangenberg, D., Sun-Mack, S., and Wind, G.: Comparison of CALIPSO-Like, LaRC, and MODIS Retrievals of Ice-Cloud Properties over SIRTA in France and Florida during CRYSTALFACE, J. Appl. Met. Clim., 46, 249-272, 2007.

Clerbaux, C., Coheur, P. F., Clarisse, L., Hadji-Lazaro, J., Hurtmans, D., Turquety, S., Bowman, K., Worden, H., and Carn, S. A.: Measurements of SO 2profiles in volcanic plumes from the NASA Tropospheric Emission Spectrometer (TES), Geophys. Res. Lett., 35, L22807, doi:10.1029/2008GL035566, 2008.

Corti, T., Luo, B. P., de Reus, M., Brunner, D., Cairo, F., Mahoney, M. J., Martucci, G., Matthey, R., Mitev, V., dos Santos, F. H., Schiller, C., Shur, G., Sitnikov, N. M., Spelten, N., Vossing, H. J., Borrmann, S., and Peter, T.: Unprecedented evidence for deep convection hydrating the tropical stratosphere, Geophys. Res. Lett., 35, L10810, doi:10.1029/2008GL033641, 2008.

Davis, S. M., Avallone, L. M., Weinstock, E. M., Twohy, C. H., Smith, J. B., and Kok, G. L.: Comparisons of in situ measurements of cirrus cloud ice water content, J. Geophys. Res., 112, D10212, doi:10.1029/2006JD008214, 2007.

Davis, S., Hlavkaet, D., Jensen, E., Rosenlof, K., Yang, Q., Schmidt, S., Borrmann, S., Frey, W., Lawson, P., Voemel, H., and Bui, T. P.: In situ and lidar observations of tropopause subvisible cirrus clouds during TC4, J. Geophys. Res., 115, D00J17, doi:10.1029/2009JD013093, 2010.

Dee, D. P., Uppala, S. M., Simmons, A. J., Berrisford, P., Poli, P., Kobayashi, S., Andrae, U., Balmaseda, M. A., Balsamo, G., Bauer, P., Bechtold, P., Beljaars, A. C. M., van de Berg, L., Bidlot, J., Bormann, N., Delsol, C., Dragani, R., Fuentes, M., Geer, A. J., Haimberger, L., Healy, S. B., Hersbach, H., Hólm, E. V., Isaksen, L., Kållberg, P., Köhler, M., Matricardi, M., McNally, A. P., Monge-Sanz, B. M., Morcrette, J.-J., Park, B.-K., Peubey, C., de Rosnay, P., Tavolato, C., Thépaut, J.-N., and Vitart, F.: The ERA-Interim reanalysis: configuration and performance of the data assimilation system, Q. J. Roy. Meteorol. Soc., 137, 553597, 2011.

Dupont, J.-C., Haeffelin, M., Morille, Y., Noel, V., Keckhut, P., Winker, D., Comstock, J. M., Chervet, P., and Robin, A.: Macrophysical and optical properties of midlatitude cirrus clouds from 4 ground-based lidars and collocated CALIOP observations, J. Geophys. Res., 115, D00H24, doi:10.1029/2009JD011943, 2010.

Filipiak, M. J., Harwood, R. S., Jiang, J. H., Li, Q., Livesey, N. J., Manney, G. L., Read, W. G., Schwartz, M. J., Waters, J. W., and $\mathrm{Wu}, \mathrm{D}$. L.: Carbon monoxide measured by the EOS Microwave Limb Sounder on Aura: First results, Geophys. Res. Lett., 32, L14825, doi:10.1029/2005GL022765, 2005.

Folkins, I., Bernath, P., Boone, C., Lesins, G., Livesey, N., Thompson, A. M., Walker, K., and Witte, J. C.: Seasonal cycles of $\mathrm{O}_{3}$, $\mathrm{CO}$, and convective outflow at the tropical tropopause, Geophys. Res. Lett., 33, L16802, doi:10.1029/2006GL026602, 2006.

Froyd, K. D., Murphy, D. M., Lawson, P., Baumgardner, D., and Herman, R. L.: Aerosols that form subvisible cirrus at the tropical tropopause, Atmos. Chem. Phys., 10, 209-218, doi:10.5194/acp10-209-2010, 2010.

Fueglistaler, S., Dessler, A. E., Dunkerton, T. J., Folkins, I., Fu, Q., and Mote, P. W.: Tropical Tropopause Layer, Rev. Geophys., 47, RG1004, doi:10.1029/2008RG000267, 2009.

Grenier, P. and Blanchet, J.-P.: Investigation of the sulphateinduced freezing inhibition effect from CloudSat and 
CALIPSO measurements, J. Geophys. Res., 115, D22205, doi:10.1029/2010JD013905, 2010.

Haladay, T. and Stephens, G.: Characteristics of tropical thin cirrus clouds deduced from joint CloudSat and CALIPSO observations, J. Geophys. Res., 114, D00A25, doi:10.1029/2008JD010675, 2009.

Heymsfield, A. J.: Ice particles observed in a cirriform cloud at $-83^{\circ}$ and implications for polar stratospheric clouds, J. Geophys. Sci., 43, 851-855, 1986.

James, R. and Legras, B.: Mixing processes and exchanges in the tropical and the subtropical UT/LS, Atmos. Chem. Phys., 9, 2538, doi:10.5194/acp-9-25-2009, 2009.

Janowiak, J. E., Joyce, R. J., and Yarosh, Y.: A Real-Time Global Half-Hourly Pixel-Resolution Infrared Dataset and Its Applications, B. Am. Meteorol. Soc., 82, 205-218, doi:10.1175/1520-

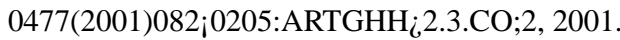

Jensen, E. J., Toon, O. B., Pster, L., and Selkirk, H. B.: Dehydration of the upper troposphere and lower stratosphere by subvisible cirrus clouds near the tropical tropopause, Geophys. Res. Lett., 23, 825-828, 1996.

Jensen, E. J., Pfister, L., Ackerman, A., Tabazadeh, A., and Toon, O.: A conceptual model of the dehydration of air due to freezedrying by optically thin, laminar cirrus rising slowly across the tropical tropopause, J. Geophys. Res., 106, 17237-17252, 2001.

Jensen, E. J., Pfister, L., Bui, T.-P., Lawson, P., and Baumgardner, D.: Ice nucleation and cloud microphysical properties in tropical tropopause layer cirrus, Atmos. Chem. Phys., 10, 1369-1384, doi:10.5194/acp-10-1369-2010, 2010.

Karagulian, F., Clarisse, L., Clerbaux, C., Prata, A. J., Hurtmans, D., and Coheur, P. F.: Detection of volcanic $\mathrm{SO}_{2}$, ash, and $\mathrm{H} 2 \mathrm{SO} 4$ using the Infrared Atmospheric Sounding Interferometer (IASI), J. Geophys. Res., 115, D00L02, doi:10.1029/2009JD012786, 2010.

Kärcher, B.: Properties of subvisible cirrus clouds formed by homogeneous freezing, Atmos. Chem. Phys., 2, 161-170, doi:10.5194/acp-2-161-2002, 2002.

Kärcher, B. and Koop, T.: The role of organic aerosols in homogeneous ice formation, Atmos. Chem. Phys., 5, 703-714, doi:10.5194/acp-5-703-2005, 2005.

Krämer, M., Schiller, C., Ziereis, H., Ovarlez, J., and Bunz, H.: Nitric acid partitioning in cirrus clouds: the role of aerosol particles and relative humidity, Tellus, 58, 141-147, 2006.

Krämer, M., Schiller, C., Afchine, A., Bauer, R., Gensch, I., Mangold, A., Schlicht, S., Spelten, N., Sitnikov, N., Borrmann, S., de Reus, M., and Spichtinger, P.: Ice supersaturations and cirrus cloud crystal numbers, Atmos. Chem. Phys., 9, 3505-3522, doi:10.5194/acp-9-3505-2009, 2009.

Lawson, R. P., Pilson, B., Baker, B., Mo, Q., Jensen, E., Pfister, L., and Bui, P.: Aircraft measurements of microphysical properties of subvisible cirrus in the tropical tropopause layer, Atmos. Chem. Phys., 8, 1609-1620, doi:10.5194/acp-8-1609-2008, 2008.

Lee, J., Yang, P., Dessler, A. E., Gao, B.-C., and Platnick, S.: Distribution and radiative forcing of tropical thin cirrus clouds, J. Atmos. Sci., 66, 3721-3731, 2009.

Legras, B., Pisso, I., Berthet, G., and Lefèvre, F.: Variability of the Lagrangian turbulent diffusion in the lower stratosphere, Atmos. Chem. Phys., 5, 1605-1622, doi:10.5194/acp-5-1605-2005, 2005.
Lohmann, U. and Diehl, K.: Sensitivity Studies of the Importance of Dust Ice Nuclei for the Indirect Aerosol Effect on Stratiform Mixed-Phase Clouds, J. Atmos. Sci., 63, 968-982, doi:10.1175/JAS3662.1, 2006.

Lohmann, U., Kärcher, B., and Timmreck, C.: Impact of the Mount Pinatubo eruption on cirrus clouds formed by homogeneous freezing in the ECHAM4 GCM, J. Geophys. Res., 108, 4568, doi:10.1029/2002JD003185, 2003.

Martins, E., Noel, V., and Chepfer, H.: Properties of cirrus and subvisible cirrus from nighttime Cloud-Aerosol Lidar Orthogonal Polarization (CALIOP), related to atmospheric dynamics and water vapor, J. Geophys. Res., 116, D02208, doi:10.1029/2010JD014519, 2011.

Massie, S. T., Gille, J., Craig, C., Khosravi, R., Barnett, J., Read, W., and Winker, D.: HIRDLS and CALIPSO observations of tropical cirrus, J. Geophys. Res., 115, D00H11, doi:10.1029/2009JD012100, 2010.

McFarquhar G. M., Heymsfield A. J., Spinhirne J., and Hart, B.: Thin and subvisual tropopause tropical cirrus: observations and radiative impacts, J. Atmos. Sci., 57, 1841-1853, 2000.

Murray, B. J.: Inhibition of ice crystallisation in highly viscous aqueous organic acid droplets, Atmos. Chem. Phys., 8, 54235433, doi:10.5194/acp-8-5423-2008, 2008.

Noel, V. and Chepfer, H.: Reply to comment by Poole et al. on "A tropical 'NAT-like' belt observed from space", Geophys. Res. Lett., 36, L20804, doi:10.1029/2009GL039689, 2009.

Noel, V., Winker, D. M., Garrett, T. J., and McGill, M.: Extinction coefficients retrieved in deep tropical ice clouds from lidar observations using a CALIPSO-like algorithm compared to in-situ measurements from the cloud integrating nephelometer during CRYSTAL-FACE, Atmos. Chem. Phys., 7, 1415-1422, doi:10.5194/acp-7-1415-2007, 2007.

Noel, V., Hertzog, A., Chepfer, H., and Winker, D.: Polar Stratospheric Clouds over Antarctica from the CALIPSO spaceborne lidar, J. Geophys. Res., 113, D0225, doi:10.1029/2007JD008616, 2008.

Pan, L. L. and Munchak, L. A.: Relationship of cloud top to the tropopause and jet structure from CALIPSO data, J. Geophys. Res., 116, D12201, doi:10.1029/2010JD015462, 2011.

Peter, Th., Luo, B. P., Wirth, M., Kiemle, C., Flentje, H., Yushkov, V. A., Khattatov, V., Rudakov, V., Thomas, A., Borrmann, S., Toci, G., Mazzinghi, P., Beuermann, J., Schiller, C., Cairo, F., Di Donfrancesco, G., Adriani, A., Volk, C. M., Strom, J., Noone, K., Mitev, V., MacKenzie, R. A., Carslaw, K. S., Trautmann, T., Santacesaria, V., and Stefanutti, L.: Ultrathin Tropical Tropopause Clouds (UTTCs): I. Cloud morphology and occurrence, Atmos. Chem. Phys., 3, 1083-1091, doi:10.5194/acp-3-1083-2003, 2003.

Peter, T., Marcolli, C., Spichtinger, P., Corti, T., Baker, M. B., and Koop, T.: When dry air is too humid, Science, 314, 1399-1402, 2006.

Petters, M. D., Carrico, C. M., Kreidenweis, S. M., Prenni, A. J., DeMott, P. J., Collett Jr., J. R., and Moosmüller, H.: Cloud condensation nucleation activity of biomass burning aerosol, J. Geophys. Res., 114, D22205, doi:10.1029/2009JD012353, 2009.

Pisso, I. and Legras, B.: Turbulent vertical diffusivity in the sub-tropical stratosphere, Atmos. Chem. Phys., 8, 697-707, doi:10.5194/acp-8-697-2008, 2008. 
Platt, C. M. R., Young, S. A., Austin, R. T., Patterson, G. R., Mitchell, D. L., and Miller, S. D.: LIRAD Observations of Tropical Cirrus Clouds in MCTEX. Part I: Optical Properties and Detection of Small Particles in Cold Cirrus, J. Atmos. Sci., 59, 3145-3162, 2002.

Poole, L. R., Pitts, M. C., and Thomason, L. W.: Comment on "A tropical 'NAT-like' belt observed from space" by H. Chepfer and V. Noel, Geophys. Res. Lett., 36, L20803, doi:10.1029/2009GL038506, 2009.

Popp, P. J., Gao, R. S., Marcy, T. P., Fahey, D. W., Hudson, P. K., Thompson, T. L., Kärcher, B., Ridley, B. A., Weinheimer, A. J., Knapp, D. J., Montzka, D. D., Baumgardner, D. G., Garrett, T. J., Weinstock, E. M., Smith, J. B., Sayres, D. S., Pittman, J. V., Dhaniyala, S., Bui, T. P., and Mahoney, M. J.: Nitric acid uptake on subtropical cirrus cloud particles, J. Geophys. Res., 109, D06302, doi:10.1029/2003JD004255, 2004.

Popp, P. J., Marcy, T. P., Jensen, E. J., Kärcher, B., Fahey, D. W., Gao, R. S., Thompson, T. L., Rosenlof, K. H., Richard, E. C., Herman, R. L., Weinstock, E. M., Smith, J. B., May, R. D., Vömel, H., Wilson, J. C., Heymsfield, A. J., Mahoney, M. J., and Thompson, A. M.: The observation of nitric acid-containing particles in the tropical lower stratosphere, Atmos. Chem. Phys., 6, 601-611, doi:10.5194/acp-6-601-2006, 2006.

Prata, A. J., Carn, S. A., Stohl, A., and Kerkmann, J.: Long range transport and fate of a stratospheric volcanic cloud from Soufrière Hills volcano, Montserrat, Atmos. Chem. Phys., 7, 5093-5103, doi:10.5194/acp-7-5093-2007, 2007.

Riihimaki, L. D. and McFarlane, S. A.: Frequency and morphology of tropical tropopause layer cirrus from CALIPSO observations: Are isolated cirrus different from those connected to deep convection?, J. Geophys. Res., 115, D18201, doi:10.1029/2009JD013133, 2010.

Sassen, K.: The Polarization Lidar Technique for Cloud Research: A Review and Current Assessment, B. Am. Meteor. Soc., 72, 1848-1866, 1991.

Sassen, K. and Benson, S.: A midlatitude Cirrus Cloud Climatology from the Facility for Atmospheric Remote Sensing. Part II: microphysical properties derived from lidar depolarisation, J. Atmos. Sci., 58, 2103-2112, 2001.

Sassen, K. and Cho, B. S.: Subvisual-thin cirrus lidar dataset for satellite verification and climatological research, J. Appl. Meteor., 31, 1275-1285, 1992.

Sassen, K., Wang, Z., and Liu, D.: Global distribution of cirrus clouds from CloudSat/Cloud-Aerosol Lidar and Infrared Pathfinder Satellite Observations (CALIPSO) measurements, J. Geophys. Res., 113, D00A12, doi:10.1029/2008JD009972, 2008.

Sassen, K., Wang, Z., and Liu, D.: Cirrus clouds and deep convection in the tropics: Insights from CALIPSO and CloudSat, J. Geophys. Res., 114, D00H06, doi:10.1029/2009JD011916, 2009.

Schwartz, M. C. and Mace, G. G.: Co-occurrence statistics of tropical tropopause layer cirrus with lower cloud layers as derived from CloudSat and CALIPSO data, J. Geophys. Res., 115, D20215, doi:10.1029/2009JD012778, 2010.

Sherwood, S., Minnis, P., McGill, M., and Chae, J.: Underestimation of Deep Convective Clouds Tops by Thermal Imagery, Geophys. Res. Lett., 31, L11102, doi:10.1029/2004GL019699, 2004.
Solomon, S., Rosenlof, K. H., Portmann, R. W., Daniel, J. S., Davis, S. M., Sanford, T. J., and Plattner, G.-K.: Contributions of stratospheric water vapor to decadal changes in the rate of global warming, Science, 327, 1219-1223, 2010.

Spichtinger, N., Wenig, M., James, P., Wagner, T., Platt, U., and Stohl, A.: Satellite detection of a continental-scale plume of nitrogen oxides from boreal forest fires, Geophys. Res. Lett., 28, 4579-4582, 2001.

Stohl, A., Forster, C., Frank, A., Seibert, P., and Wotawa, G.: Technical note: The Lagrangian particle dispersion model FLEXPART version 6.2, Atmos. Chem. Phys., 5, 2461-2474, doi:10.5194/acp-5-2461-2005, 2005.

Theys, N., Van Roozendael, M., Dils, B., Hendrick, F., Hao, N., and De Mazière, M.: First satellite detection of volcanic bromine monoxide emission after the Kasatochi eruption, Geophys. Res. Lett., 36, L03809, doi:10.1029/2008GL036552, 2009.

Thomas, A., Borrmann, S., Kiemle, C., Cairo, F., Volk, M., Beuermann, J., Lepuchov, B., Santacesaria, V., Matthey, R., Rudakov, V., Yushkov, V., MacKenzie, A. R., and Stefanutti, L.: In situ measurements of background aerosol and subvisible cirrus in the tropical tropopause region, J. Geophys. Res., 107, 4763, doi:10.1029/2001JD001385, 2002.

Toon, O. B., Starr, D. O., Jensen, E. J., Newman, P. A., Platnick, S., Schoeberl, M. R., Wennberg, P. O., Wofsy, S. C., Kurylo, M. J., Maring, H., Jucks, K. W., Craig, M. S., Vasques, M. F., Pfister, L., Rosenlof, K. H., Selkirk, H. B., Colarco, P. R., Kawa, S. R., Mace, G. G., Minnis, P., and Pickering, K. E.: Planning, implementation, and first results of the Tropical Composition, Cloud and Climate Coupling Experiment (TC4), J. Geophys. Res., 115, D00J04, doi:10.1029/2009JD013073, 2010.

Tzella, A. and Legras, B.: A Lagrangian view of convective sources for transport of air across the Tropical Tropopause Layer: distribution, times and the radiative influence of clouds, Atmos. Chem. Phys., 11, 12517-12534, doi:10.5194/acp-11-12517-2011, 2011.

Vaughan, M. A., Liu, Z., McGill, M. J., Hu, Y., and Obland, M. D.: On the spectral dependence of backscatter from cirrus clouds: Assessing CALIOP's $1064 \mathrm{~nm}$ calibration assumptions using cloud physics lidar measurements, J. Geophys. Res., 115, D14206, doi:10.1029/2009JD013086, 2010.

Vernier, J.-P., Thomason, L. W., Pommereau, J.-P., Bourassa, A., Pelon, J., Garnier, A., Hauchecorne, A., Blanot, L., Trepte, C., Degenstein, D., and Vargas, F.: Major influence of tropical volcanic eruptions on the stratospheric aerosol layer during the last decade, Geophys. Res. Lett., 38, L12807, doi:10.1029/2011GL047563, 2011a.

Vernier, J.-P., Pommereau, J.-P., Thomason, L. W., Pelon, J., Garnier, A., Deshler, T., Jumelet, J., and Nielsen, J. K.: Overshooting of clean tropospheric air in the tropical lower stratosphere as seen by the CALIPSO lidar, Atmos. Chem. Phys., 11, 96839696, doi:10.5194/acp-11-9683-2011, 2011b.

Vernier, J.-P., Thomason, L. W., and Kar, J.: CALIPSO detection of an Asian tropopause aerosol layer, Geophys. Res. Lett., 38, L07804, doi:10.1029/2010GL046614, 2011c.

Virts, K. S., Wallace, J. M., Fu, Q., and Ackerman, T. P.: Tropical Tropopause Transition Layer Cirrus as Represented by CALIPSO Lidar Observations, J. Atmos. Sci., 67, 3113-3129, doi:10.1175/2010JAS3412.1, 2010.

Voigt, C., Schreiner, J., Kohlmann, A., Zink, P., Mauersberger, K., Larsen, N., Deshler, T., 15 Kröger, C., Rosen, J., Adriani, A., 
Cairo, F., Di Donfrancesco, G., Viterbini, M., Ovarlez, J., Ovarlez, H., David, C., and Dörnbrack, A.: Nitric Acid Trihydrate (NAT) in Polar Stratospheric Clouds, Science, 290, 1756-1758, doi:10.1126/science.290.5497.1756, 2000.

Voigt, C., Kärcher, B., Schlager, H., Schiller, C., Krämer, M., de Reus, M., Vössing, H., Borrmann, S., and Mitev, V.: In-situ observations and modeling of small nitric acid-containing ice crystals, Atmos. Chem. Phys., 7, 3373-3383, doi:10.5194/acp7-3373-2007, 2007.

Voigt, C., Schlager, H., Roiger, A., Stenke, A., de Reus, M., Borrmann, S., Jensen, E., Schiller, C., Konopka, P., and Sitnikov, N.: Detection of reactive nitrogen containing particles in the tropopause region - evidence for a tropical nitric acid trihydrate (NAT) belt, Atmos. Chem. Phys., 8, 7421-7430, doi:10.5194/acp-8-7421-2008, 2008.

Wang, P.-H., McCormick, M. P., Poole, L. R., Chu, W. P., Yue, G. K., Kent, G. S., and Skeens, K. M.: Tropical high cloud characteristics derived from SAGE II extinction measurements, Atmos. Res., 34, 53-83, 1994.

Wang, T. and Dessler, A. E.: Analysis of cirrus in the tropical tropopause layer from CALIPSO and MLS data: A water perspective, J. Geophys. Res., 117, D04211, doi:10.1029/2011JD016442, 2012.
Weigel, R., Borrmann, S., Kazil, J., Minikin, A., Stohl, A., Wilson, J. C., Reeves, J. M., Kunkel, D., de Reus, M., Frey, W., Lovejoy, E. R., Volk, C. M., Viciani, S., D’Amato, F., Schiller, C., Peter, T., Schlager, H., Cairo, F., Law, K. S., Shur, G. N., Belyaev, G. V., and Curtius, J.: In situ observations of new particle formation in the tropical upper troposphere: the role of clouds and the nucleation mechanism, Atmos. Chem. Phys., 11, 9983-10010, doi:10.5194/acp-11-9983-2011, 2011.

Winker, D. M, Vaughan, M. A., Omar, A., Hu, Y., and Powell, K. A.: Overview of the CALIPSO mission and CALIOP data processing algorithms, J. Atmos. Ocean. Tech., 26, 2310-2322, 2009.

Yang, K., Krotkov, N. A., Krueger, A. J., Carn, S. A., Bhartia, P. K., and Levelt, P. F.: Retrieval of large volcanic $\mathrm{SO}_{2}$ columns from the Aura Ozone Monitoring Instrument: Comparison and limitations, J. Geophys. Res., 112, D24S43, doi:10.1029/2007JD008825, 2007.

Yang, Q., Fu, Q., and Hu, Y.: Radiative impacts of clouds in the tropical tropopause layer, J. Geophys. Res., 115, D00H12, doi:10.1029/2009JD012393, 2010. 